Check for updates

Cite this: RSC Adv., 2019, 9, 38505

\title{
Kinetically-controlled mechanism-based isolation of metabolic serine hydrolases in active form from complex proteomes: butyrylcholinesterase as a case study $\dagger$
}

\begin{abstract}
Hui Liu, Huimin Zhou, Huaqiao Du, Qiaoling Xiao and Marco Pistolozzi (iD *
In this work an activity-based probe containing a carbamate group was designed to isolate human butyrylcholinesterase $(\mathrm{hBChE})$, a metabolic serine hydrolase $(\mathrm{mSH})$, from complex proteomes. The method took advantage of the native interaction mechanism of $\mathrm{mSH}$ s with carbamate pseudo-substrates for temporarily capturing the enzyme on a resin functionalized with the carbamate probe and releasing the enzyme in active form after removal of the contaminating proteins. The isolation relied on the possibility of manipulating the carbamylation and decarbamylation kinetics favoring the former during the capture and wash steps and the latter in the release step. The designed probe captured and released all the active $\mathrm{hBChE}$ isoenzymes present in plasma with high selectivity (up to $\sim 2000$-fold purification) and reasonable yields (17\% to $36 \%$ ). The parameters affecting the performance were the incubation time used in the load and elution steps, the plasma to resin volumetric ratio, the elution temperature and the nature and concentration of the eluting agent. The carbamate resin could be prepared either by coupling a fully synthesized probe with an activated resin or by building the probe onto the resin by a step-by-step procedure, without major differences in performance between the two routes. The prepared resins allowed to process up to about $8.5 \mathrm{~mL}$ of plasma per $\mathrm{g}$ of resin with constant performance. Since the method was based on the general catalytic cycle of $\mathrm{mSHs}$, we expect this approach to be applicable to other enzymes of the family, by selecting a suitable target-selective feature to link to the carbamate group.
\end{abstract}

Received 19th September 2019 Accepted 18th November 2019

DOI: $10.1039 / c 9 r a 07583 f$

rsc.li/rsc-advances

\section{Introduction}

Serine hydrolases (SHs) constitute a large class of enzymes that catalyze the hydrolysis of esters, amides, or thioester groups of small molecules, peptides, and proteins. In mammals, this class comprises more than 200 enzymes including serine proteases (e.g. trypsin, chimotrypsin, subtilisin enzymes) and other enzymes, collectively termed "metabolic SHs" (mSHs), consisting of peptidases, lipases, esterases, thioesterases and amidases. mSHs are known for their involvement in a wide range of (patho)physiological pathways, however, despite their importance, a large part of them has yet not been fully characterized. $^{1-4}$ mSHs share a similar catalytic cycle in which

School of Biology \& Biological Engineering, South China University of Technology, Higher Education Mega Center, Guangzhou, People's Republic of China. E-mail: marco_pistolozzi@scut.edu.cn

$\dagger$ Electronic supplementary information (ESI) available: Chemicals, reagents and solvents; general methods for the chemical synthesis; synthesis of the solid-supported probes; determination of the amount of active carbonate groups on the resins; measurement of $\mathrm{hBChE}$ activity; sample preparation for the proteomic analysis; Scheme S1; ${ }^{1} \mathrm{H}-\mathrm{NMR},{ }^{13} \mathrm{C}-\mathrm{NMR}$ and HRMS spectra. See DOI: $10.1039 / \mathrm{c} 9 \mathrm{ra0} 7583 \mathrm{f}$ a characteristic nucleophilic serine reacts with the substrate, forming an acyl-enzyme ester intermediate that is quickly hydrolized by water. ${ }^{2}$ In addition to the natural substrates, other molecules bearing carbamate and organophosphate groups can act as $\mathrm{mSH}$ substrates ${ }^{4-6}$ (Fig. 1a), albeit with low efficiency, and for this reason are regarded as pseudo-substrates. In fact, since the hydrolysis of the acyl-enzyme is much slower when the acyl group is a carbamate or a phosphonate rather than an ester, the reaction of mSHs with pseudo-substrates results in the formation of adducts with significantly longer lifespan than those formed with the natural substrates. ${ }^{7,8}$ In the case of recombinant enzymes, the use of a His-tag enables a simple, often single-step, purification of active mSHs through immobilized metal affinity chromatography (IMAC) or metal oxides $(\mathrm{MOAC})^{9,10}$ and other similar methods based on magnetic micro- and nanoparticles. ${ }^{11,12}$ Very promising purification strategies based on cleavable self-aggregating $\operatorname{tags}^{13}$ have recently emerged, and might replace IMAC and MOAC strategies in the future. However, the isolation of untagged $\mathrm{mSHs}$ from their native complex proteomes is still a very challenging task and several techniques are often necessary to obtain a pure enzyme preparation, ${ }^{14-16}$ making $\mathrm{mSHs}$ isolation time- 
a

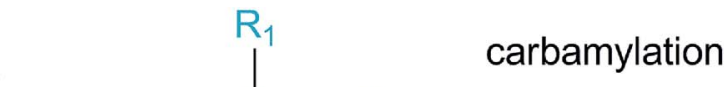

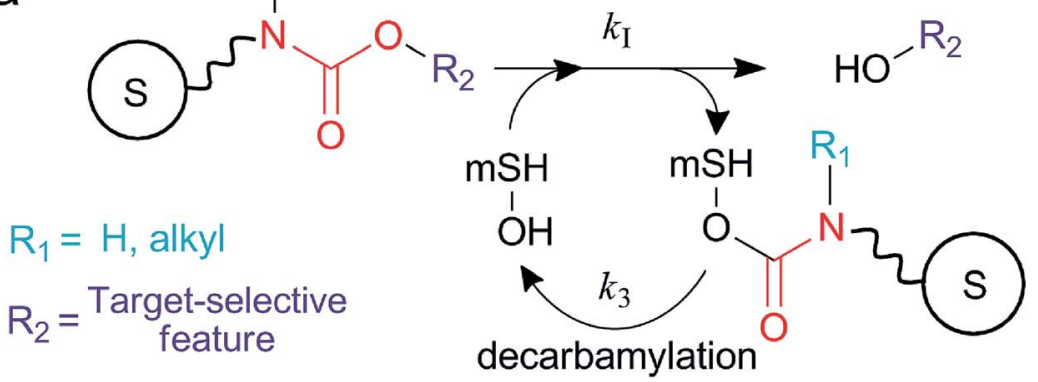

b<smiles>[C+]1CCCC1</smiles><smiles>[Hg][Hg]</smiles>

Step 1. Load<smiles>C1CCCCC1</smiles><smiles>CN(O)OC(=O)O</smiles><smiles>C1CCCCC1</smiles>

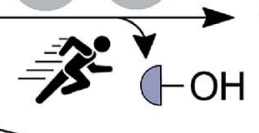<smiles>C#CCNc1ccccc1</smiles>

$\mathrm{mSH}$ decarbamylation

$\mathrm{S}$ 
consuming, labor-intensive and rather expensive. In virtue of their pseudo-substrate behaviour, organophosphonates have been used to design activity-based probes that could be used to monitor mSHs activity in complex proteomes using a strategy known as activity-based protein profiling (ABPP). ${ }^{\mathbf{1 4 , 1 7 - 2 0}}$ In the frame of $\mathrm{mSHs}$, this chemoproteomic strategy employs a probe containing a fluorophosphonate function at one end that targets the active site of $\mathrm{mSHs}$ forming irreversible adducts. The other end of the probe is functionalized with a reporter tag (e.g., a fluorescent molecule such as rhodamine) that allows selective detection of the targeted mSHs after SDS-PAGE separation. This approach has been used to study quantitative differences of mSHs activity in different conditions ${ }^{21}$ or, in a competitive format, to find new ligands targeting the active site of $\mathrm{mSHs}$ and test their specificity, ${ }^{22}$ and to find off-targets of environmental pesticides..$^{23,24}$ In addition to their use for monitoring purposes, if opportunely functionalized (e.g. with an affinity or a clickable tag), such probes can be used for the enrichment of mSHs for subsequent identification by MS analysis. However, since these probes bind irreversibly to the active site, the enzymes are isolated as the inactive probe-conjugates. In other works in which the phosphonate probe was directly linked to a chromatographic material, the target enzyme could not be recovered, ${ }^{25}$ or required the use of strong nucleophilic reagents to restore the native active site. ${ }^{26,27}$ Therefore such probes cannot be easily used if an active enzyme is desired. Due to these limitations, we explored the possibility to isolate selected mSHs from complex proteomes using activity-based carbamate probes. The proposed approach consists in substituting one of the $N$-alkyl groups of the carbamate moiety of a suitable enzyme pseudosubstrate with a spacing arm that is covalently attached to a solid surface (Fig. 1). Upon incubation of the proteome with the functionalized solid, the enzyme reacts with the carbamate moiety and a certain amount, which depends on the carbamylation and decarbamylation rates, is constantly attached to the solid surface as a carbamate adduct (i.e., with a covalent bond) allowing the removal of unbound or reversibly bound contaminating proteins by rapidly washing with large volumes of a suitable buffer. Then, in virtue of the native capacity of the enzyme to slowly hydrolyze the covalent carbamyl-enzyme bond, it would be possible to recover the active enzyme by simply modifying the equilibrium between carbamylation and decarbamylation. To test the principle of this approach we selected human butyrylcholinesterase (EC 3.1.1.8, hBChE) as the model $\mathrm{mSH}$ and human plasma as the model proteome.

\section{Results and discussion}

\subsection{Probe design}

The design of the carbamate probe was based on the structure of bambuterol monocarbamate (MONO), a product of the bioconversion of the BChE inhibitor bambuterol (BMB).,28 MONO can react with ChEs following the general pseudosubstrate mechanism with high potency and selectivity towards hBChE, ${ }^{7,29}$ thus representing a suitable lead structure to characterize this activity-based method. Since the decarbamylation rate constant $\left(k_{3}\right)$ of carbamyl-ChEs is modulated by the number and nature of the substituents on the carbamic nitrogen, and in general monoalkylated carbamates are hydrolyzed faster than dialkylated ones, ${ }^{30-32}$ one of the $N$-methyl groups of MONO was removed to increase the decarbamylation kinetics which, according to the working hypothesis, is a key parameter modulating the elution rate of the enzyme from the resin. The other $N$-methyl group was substituted with a flexible spacing arm which was then linked to sepharose (Fig. 1c).

\subsection{Synthesis of the probe and kinetic characterization of its interaction with hBChE}

The synthesis of the probe involved two activation steps and $N, N^{\prime}$-carbonyldiimidazole (CDI) was used as the activating reagent for both of them (Strategy 1, Scheme 1). First it was used as a zero-length crosslinker to form an amide bond between Boc-6-aminohexanoic acid (Boc-6Ahx) and 4,7,10-trioxa-1,13tridecanediamine (TTD), then it was used as a one-carbon spacer to form a carbamate bond between the amino-end of Boc-6Ahx-TTD (1) and one of the phenol groups of terbutaline

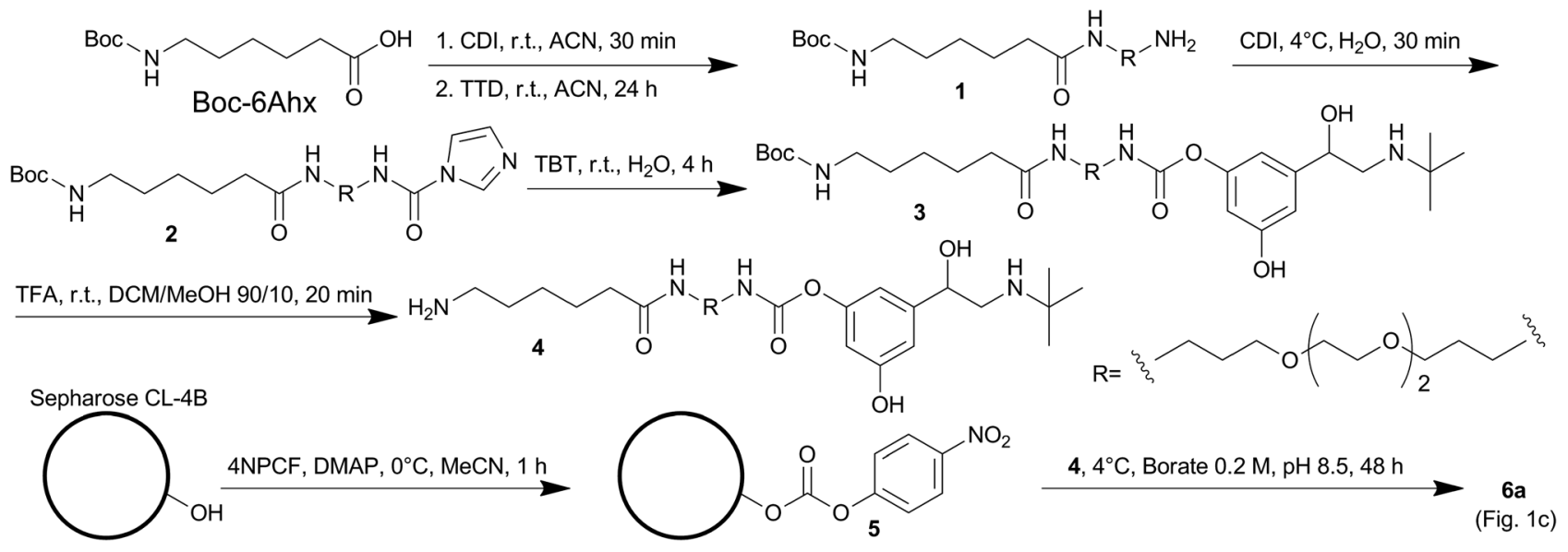

Scheme 1 Synthesis of sepharose-6Ahx-TTD-TBT 6a (Strategy 1). Boc-6Ahx, Boc-6-aminohexanoic acid; CDI N,N'-carbonyldiimidazole; TTD, 4,7,10-trioxa-1,13-tridecanediamine; TBT, rac-terbutaline hemisulfate; 4NPCF, p-nitrophenyl chloroformate; DMAP, 4-(dimethylamino)pyridine. 
(TBT) to form compound 3. The imidazolyl urea intermediate (compound 2) was isolated for characterization, although the reaction could be performed one-pot. ${ }^{33}$ The kinetic characterization of compound 3 indicated that the introduction of the spacing arm in the structure of MONO did not significantly modify the bimolecular carbamylation rate constant $\left(k_{\mathrm{I}}\right)$, while the removal of one of the $N$-methyl groups increased the $k_{3}$, as expected (Fig. 2 and Table 1). In addition, since a linear correlation was obtained by plotting the pseudo-first order kinetic constants $\left(k_{\text {obs }}\right)$ against the inhibitor concentrations up to $2 \mu \mathrm{M}$, the analysis indicated that the probe has a relatively low affinity (high $K_{\mathrm{D}}$ ) for hBChE, likely above $20 \mu \mathrm{M}$.

\subsection{Synthesis and characterization of the carbamate resins 6a (Strategy 1) and 6b (Strategy 2)}

Compound 3 was deprotected to form compound $\mathbf{4}$, which was linked to a sepharose resin containing $p$-nitrophenyl carbonate groups (5) to obtain the final resin 6a (Strategy 1, Scheme 1 and Fig. 1). An alternative strategy (Strategy 2) involved the sequential addition of the building blocks starting from 5 to form a carbamate resin containing the same probe (6b) by using a different route (ESI, Scheme $\mathrm{S} 1 \dagger$ ). In this simplified procedure 6-aminohexanoic acid (6Ahx) was coupled to 5 to obtain a sepharose-6Ahx derivatized resin (7). The addition of TTD and $N$-(3-dimethylaminopropyl)- $N$ '-ethylcarbodiimide hydrochloride (ECD) afforded sepharose-6Ahx-TTD (8) which was then activated with CDI and reacted with TBT to form the final carbamate resin $\mathbf{6 b}$.

The amount of carbamate probe immobilized on resin $6 \mathbf{a}$ was determined by HPLC analysis of the TBT released from the resin upon alkaline treatment and resulted $5.5 \mathrm{nmol} \mathrm{mg}^{-1}$ of wet (spin filtered) resin. The same approach gave only an approximate estimation of the carbamate immobilized on resin 6b because we found that CDI was able to activate the hydroxyl groups present on the sepharose matrix and a large amount of TBT was coupled directly to the matrix. Based on the amount of TBT released from $\mathbf{6 b}$ and the amount released from a test resin prepared by reacting sepharose, CDI and TBT (i.e. without the
Table 1 Kinetic parameters of the interaction between compound 3 and hBChE

\begin{tabular}{llc}
\hline Compound & $k_{\mathrm{I}}\left(\mathrm{M}^{-1} \mathrm{~min}^{-1}\right)$ & $k_{3}\left(\times 10^{-3}, \mathrm{~min}^{-1}\right)$ \\
\hline 3 & $(7.7 \pm 0.1) \times 10^{5}$ & $57 \pm 3$ \\
MONO $^{29}$ & $(3.6 \pm 0.2) \times 10^{5}$ & $10.2 \pm 0.6$ \\
\hline
\end{tabular}

presence of the spacing arm), we estimated the amount to be in the range of $0.2-0.4 \mathrm{nmol} \mathrm{mg}{ }^{-1}$ of wet (spin filtered) resin.

\subsection{Characterization of the retention and release mechanisms}

The capability of the prepared carbamate resins to retain and release hBChE was tested by a series of single-step purification experiments in which the resins were placed on spin filters, incubated with plasma and then quickly washed with large volumes of a wash buffer. The enzyme was eluted in three fractions obtained by incubation with an elution buffer. The eluted proteins were washed and concentrated by ultracentrifugation, then an aliquot of the eluate was tested for hBChE activity to determine the yield. Another aliquot was loaded in duplicate on the left and right sides of polyacrylamide gels to evaluate the purity. The gel electrophoresis was performed in non-denaturing conditions, then the gels were cut in half and one half was developed by silver staining, the other half by BChE activity staining. Bradford assay was used for protein quantification of selected samples to determine the specific activity of hBChE and the purification factors. The results obtained with resins $\mathbf{6 a}$ and $\mathbf{6 b}$ were essentially similar. The results reported in this paper were obtained using resin $\mathbf{6 a}$, unless otherwise specified.

The incubation of plasma with the carbamate resins resulted in the expected retention and release of active hBChE (Fig. 3a). In preliminary experiments we found that (1) the incubation of plasma for 30-60 min was sufficient to bind significant amounts of hBChE, (2) most of the protein contaminants could be removed by washing the resins with a phosphate buffer at $\mathrm{pH}$
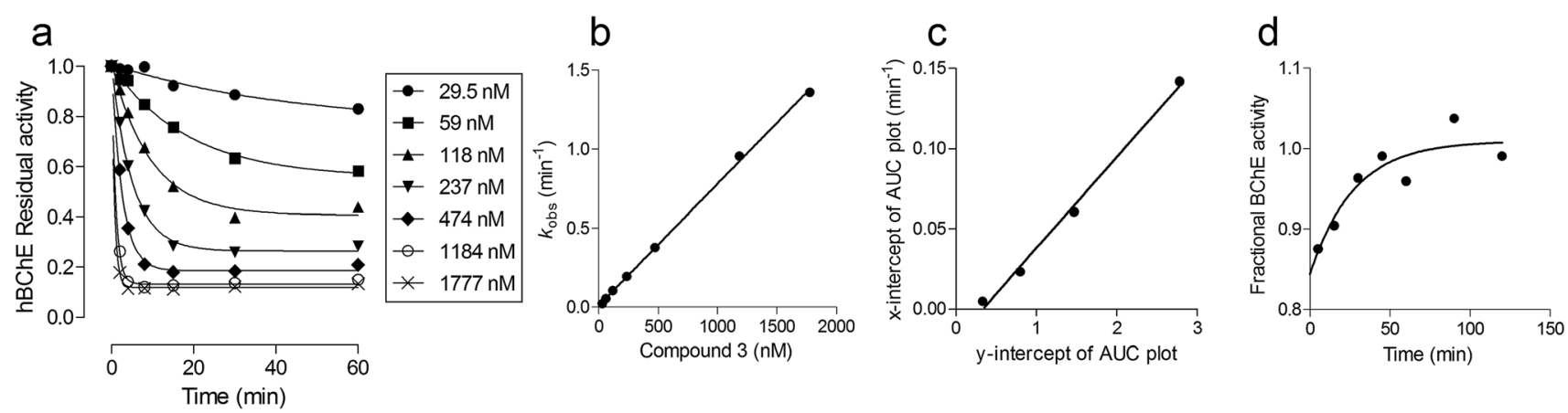

Fig. 2 (a) Time- and concentration-dependent inhibition of hBChE after pre-incubation with various concentrations of compound 3. The onephase exponential fit of the measured residual activity (solid lines) provided the $k_{\mathrm{obs}}$ values. (b) Linear correlation of the $k_{\mathrm{obs}}$ values $v s$. the concentration of compound 3. The slope of the linear regression corresponds to the bimolecular carbamylation rate constant, $k_{1}$. (c) Secondary plot obtained from the analysis the area under the inhibition-time curves (AUIC). The slope of the linear regression corresponds to the decarbamylation rate constant, $k_{3}$. (d) Recovery of hBChE activity after inhibition by compound 3 and dilution. 

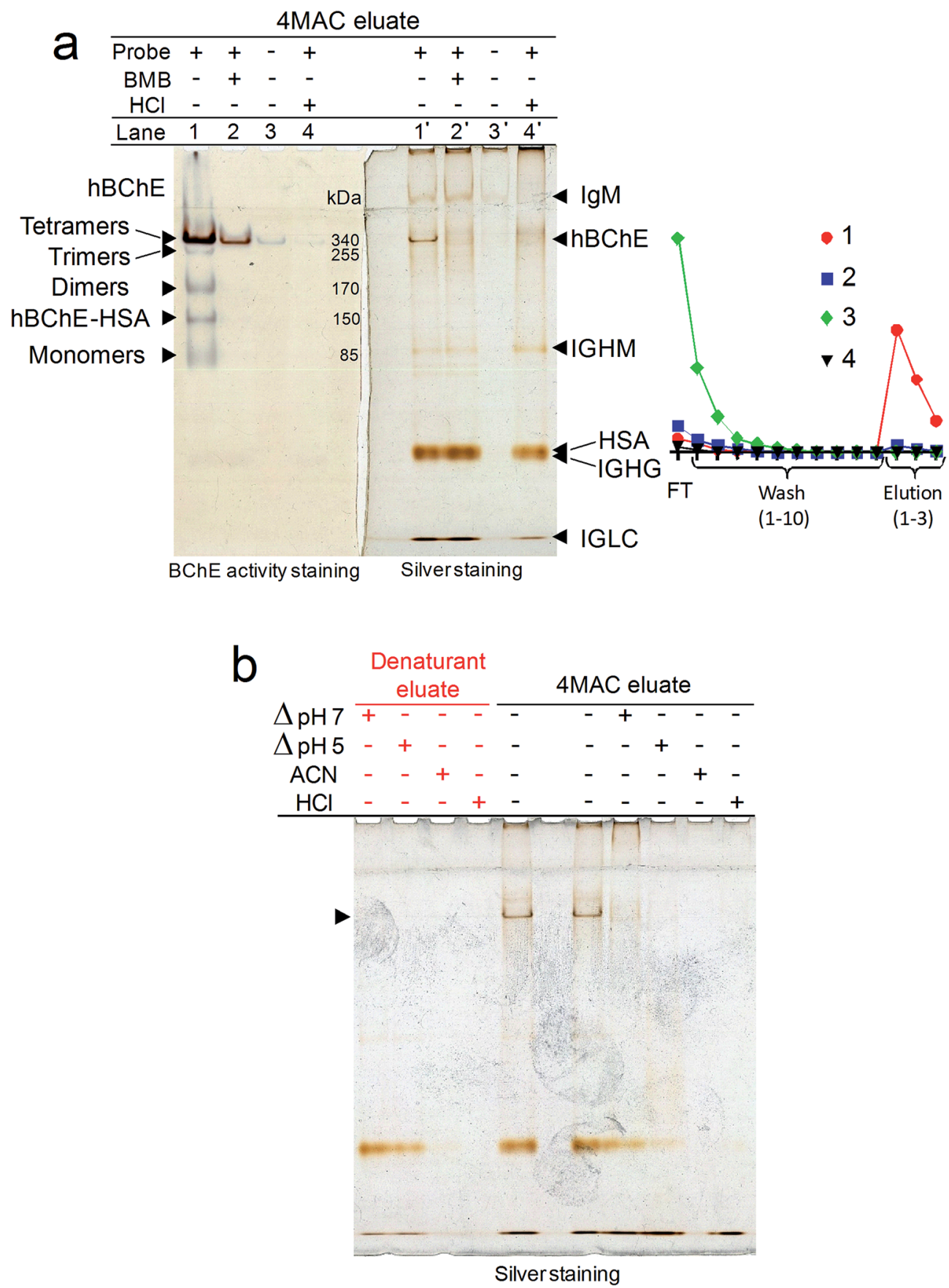

Fig. 3 (a) Left panel, non-denaturing PAGE showing the effect of active site inhibition (lane 2) and acid denaturation (lane 3) (before the load step), and the effect of the removal of the probe from the resin (lane 4) on the retention of hBChE; lane 1, untreated plasma loaded on resin containing the probe (6a); right panel, hBChE activity of the corresponding eluates; FT, flow-through fraction. (b) Non-denaturing PAGE showing the effect of denaturation (after load and wash steps) on the release of $\mathrm{hBChE}$; the arrows indicate the position of hBChE tetramers.

7 and (3) active hBChE could be eluted using tetramethylammonium chloride (4MAC), a weak hBChE activator/inhibitor. ${ }^{34}$ We used this information to characterize the retention and release mechanisms of hBChE.

The pre-incubation of plasma with BMB or the denaturation by acid treatment as well as the removal of the carbamate moieties from the resin (by alkaline treatment, before the incubation with plasma), prevented the binding of hBChE
(Fig. 3a), demonstrating that (1) the retention mechanism involved the active site, (2) only active hBChE was retained and (3) the presence of the carbamate was essential for the retention.

Temperature-, acid- and solvent-induced denaturation of the enzyme bound to the resin prevented its release (Fig. 3b), consistently with the proposed retention mechanism involving a covalent attachment of the enzyme to the resin. 
The fact that the protein contaminants were not retained when the probe was chemically stripped from the resin (Fig. 3a) is indicative of a certain binding specificity of the contaminants for the probe. However, the acid treatment had no effect on the retention and release of the contaminants indicating that either these protein are stable at low $\mathrm{pH}$ or that their binding to the probe is not particularly dependent on their folding. The fact that, with the exception of the denaturation by heat shock at $\mathrm{pH}$ 7, denaturation conditions impaired, and, in the case of acetonitrile (ACN) and acid shock, completely suppressed, also the release of most of the contaminants (Fig. 3b), suggested that also the binding of the contaminants might be covalent in nature. However, further research is required to determine the exact nature of the interaction between the contaminant proteins and the probe.

\subsection{Proteomic analysis of the eluate}

In addition to hBChE, other five major bands were observed in the silver stained gel (Fig. 3a). Proteomic analysis of the tryptic digest of the eluate indicated the presence of three main proteins in addition to hBChE (Table 2): serum albumin, and the immunoglobulins IgG and IgM. Based on this information we could tentatively assign the slowest band(s) to IgM ( 950 $\mathrm{kDa}$ and $\sim 1140 \mathrm{kDa}$ for pentamer and hexamer, respectively), which is known to remain in the stacking gel unless reduced. ${ }^{35}$ The other bands were attributed to hBChE tetramers (the main form of hBChE in plasma, $\sim 340 \mathrm{kDa}$ ), Ig heavy chain $\mu$ (IGHM, $\sim 80 \mathrm{kDa}$ ), serum albumin (HSA, $\sim 65 \mathrm{kDa}$ ), Ig heavy chain $\gamma$ (IGHG, $\sim 55 \mathrm{kDa}$ ) and Ig light chain $\lambda$ (IGLC, $\sim 25 \mathrm{kDa}$ ) (Fig. 3a). The activity-stained gel revealed the presence of small amounts of trimers, dimers, albumin adducts and monomers of hBChE in the eluate (Fig. 3a), indicating that the carbamate resins were able to retain and release all the active isoforms of hBChE normally present in plasma, ${ }^{36}$ apparently without affecting their natural composition. This is a major difference compared with other hBChE isolation methods, ${ }^{37}$ including the most recent and best performing affinity chromatographic (AC) method based on Hupresin resin, ${ }^{38}$ which were reported to retain only the tetramers.
According to the semi-quantitative data obtained from this proteomic analysis (Table 2) and the normal concentrations of hBChE, HSA and immunoglobulins in plasma (i.e. $10 \mu \mathrm{g} \mathrm{L}^{-1},{ }^{8}$ 35-50 $\mathrm{g} \mathrm{L}^{-1}, 3914 \mathrm{~g} \mathrm{~L}^{-1},{ }^{35} 1.5 \mathrm{~g} \mathrm{~L}^{-1},{ }^{35}$ for hBChE, HSA, IgG and IgM, respectively), the amount of HSA and Igs retained was below $0.05 \%$ of their initial amount. These results highlighted the high selectivity of the method since only three proteins were present in significant amounts in the eluates and only in a small fraction compared to their initial amount. The selectivity compared well with that obtained with Hupresin, which was reported to retain a much higher number of protein contaminants when used in a similar format, ${ }^{38}$ although the total amount of contaminants was comparable.

hBChE and plasma platelet-activating factor acetylhydrolase (PLA2G7) are the only mSHs known to be present in the plasma of healthy individuals, ${ }^{2,36}$ although other mSHs might be present in traces. Therefore the selectivity of the probe for mSHs cannot be inferred from data obtained with plasma and should be established by using other tissues.

\subsection{Effect of experimental parameters on the performance of the carbamate resins}

In order to find the best conditions to isolate hBChE, the effects of several experimental parameters of each step of the isolation (i.e. load, wash and elution) on the isolation performance were systematically investigated.

2.6.1. Load step. In the load step, the amount of hBChE bound did not increase significantly by increasing the incubation time from $10 \mathrm{~min}$ to $60 \mathrm{~min}$, consistently with the high carbamylation rate expected on the basis of the $k_{\mathrm{I}}$ obtained for compound 3 , while the amount of protein contaminants showed an appreciable increase over time (Fig. 4a). This indicated that a short incubation time in the load step could be an effective strategy for improving the purity of the target enzyme in the final preparation.

2.6.2. Wash step. Temperature and $\mathrm{pH}$ of the wash buffer did not significantly affect the yield, but warm buffer and $\mathrm{pH} 7$ removed the contaminating proteins more efficiently than cold buffer and pH 5 (Table 3). Neither the increase of the wash volume, nor the addition of $\mathrm{NaCl}$ (Table 3 ) to the wash buffer or

Table 2 Proteomic analysis of a sample of hBChE isolated from plasma by using resin $6 a^{a}$

\begin{tabular}{|c|c|c|c|c|c|c|c|c|}
\hline UniProt accession & Description & Score & $\begin{array}{l}\text { Average } \\
\text { mass }^{b}\end{array}$ & $\begin{array}{l}\text { Matched } \\
\text { products }\end{array}$ & $\begin{array}{l}\text { Matched } \\
\text { peptides }\end{array}$ & $\begin{array}{l}\text { Sequence } \\
\text { coverage }(\%)\end{array}$ & $\begin{array}{l}\text { Top3 peptides } \\
\text { intensity sum }\end{array}$ & $\begin{array}{l}\text { Relative mol } \\
\text { abundance }(\%)\end{array}$ \\
\hline P06276 & Butyrylcholinesterase & 207 & 68988 & 33 & 9 & 10.1 & 93615 & 22.8 \\
\hline P0CG04 & $\begin{array}{l}\text { Immunoglobulin lambda-1, } \\
\text { constant }\end{array}$ & 708 & 11519 & 23 & 3 & 31.1 & 32170 & 7.8 \\
\hline P01860 & $\begin{array}{l}\text { Immunoglobulin gamma-3 } \\
\text { heavy chain }\end{array}$ & 217 & 42313 & 30 & 7 & 16.7 & 27375 & 6.7 \\
\hline P01871 & $\begin{array}{l}\text { Immunoglobulin mu heavy } \\
\text { chain }\end{array}$ & 337 & 50124 & 43 & 13 & 23.2 & 26994 & 6.6 \\
\hline P02768 & Serum albumin & 1136 & 71363 & 226 & 42 & 52.2 & 231080 & 56.2 \\
\hline
\end{tabular}

${ }^{a}$ The sample analyzed was obtained by pooling aliquots of samples 4 and 5, (Fig. 7), as detailed in the (ESI, S6). ${ }^{b}$ The average masses indicated in the table are those reported in the UniProt database and include signal peptides whereas do not include glycosylations and other post-translational modifications. Butyrylcholinesterase and immunoglobulin heavy chains are normally glycosylated. 
a

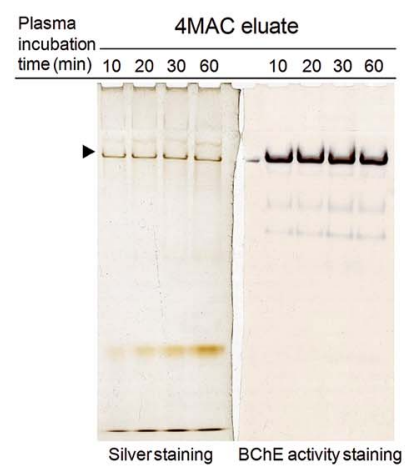

b

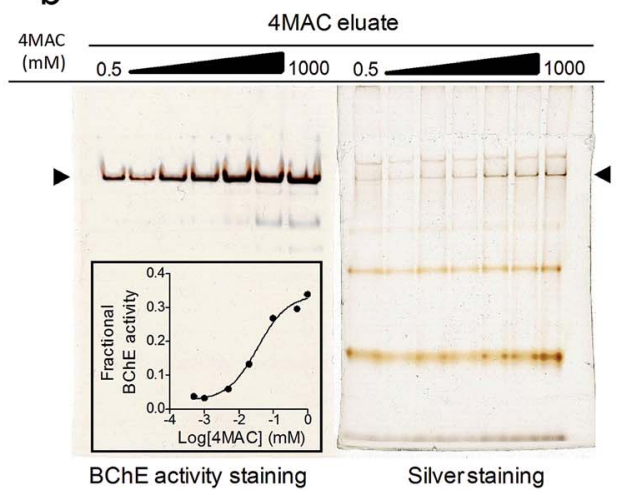

C

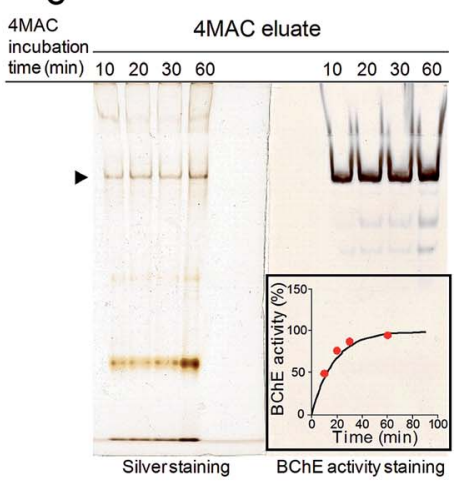

Fig. 4 (a) Non-denaturing PAGE showing the effect of plasma incubation time on protein retention; (b) non-denaturing PAGE showing the effect of different concentration of $4 \mathrm{MAC}$ on protein release; (inset) hBChE activity of the isolates versus the concentration of $4 \mathrm{MAC}$ employed for the elution (apparent $K_{\mathrm{D}}=36 \mathrm{mM}$ ); (c) non-denaturing PAGE showing the effect of $4 \mathrm{MAC}$ incubation time on protein release; (inset) comparison of the theoretical (solid line) and experimental (red circles) kinetics of the release of hBChE from the resin. The arrows indicate the position of hBChE tetramers.

Table 3 Effect of different wash conditions on hBChE yield and purity

\begin{tabular}{|c|c|c|c|c|}
\hline Variables investigated & Condition & Wash volume $(\mathrm{mL})$ & Effect on yield ${ }^{a}(\%)$ & Effect on purity ${ }^{a}(\%)$ \\
\hline \multirow[t]{3}{*}{$\mathrm{pH}$ and temperature } & $\mathrm{pH} 7,37^{\circ} \mathrm{C}$ & 5 & Reference & Reference \\
\hline & pH $5,37{ }^{\circ} \mathrm{C}$ & 5 & +20 & -62 \\
\hline & $\mathrm{pH} 5,4^{\circ} \mathrm{C}$ & 5 & +21 & -73 \\
\hline \multirow[t]{2}{*}{ Presence of $\mathrm{NaCl}$ and rinse volume } & $+\mathrm{NaCl}\left(\mathrm{pH} 7,37^{\circ} \mathrm{C}\right)$ & 5 & +11 & +11 \\
\hline & & 10 & +4 & +6 \\
\hline
\end{tabular}

${ }^{a}$ The effect is reported in percentage normalized to the yield and apparent purity obtained in the reference condition.

the treatment with HSA ligands (Table 4) before elution reduced the amount of HSA and immunoglobulins retained by the resin. As HSA ligands we tested hexanoic acid ( $\mathrm{Hx}$ ), a medium chain fatty acid with low selectivity for the different binding sites of HSA, ${ }^{40}$ salicilic acid (SAL) a ligand selective for Sudlow's site I and ibuprofen (IBU), a ligand selective for Sudlow's site II. ${ }^{\mathbf{4 1}}$ The lack of effect of HSA ligands, together with the results obtained from the denaturation experiments and the increase of contaminants observed over time in the load step are consistent with the hypothesis that the retention of HSA and Igs could be

Table 4 Effect of different elution conditions on hBChE yield and purity

\begin{tabular}{|c|c|c|c|c|}
\hline Pre-elution agent and conditions ${ }^{a}$ & Pre-elution repeats & Elution agent and conditions ${ }^{b}$ & Effect on yield ${ }^{c}(\%)$ & Effect on purity $^{c}(\%)$ \\
\hline - & - & 4MAC, pH 7 & Reference & Reference \\
\hline- & - & 4MAC, pH 5 & -8 & -20 \\
\hline - & - & TBT, pH 7 & -26 & -7 \\
\hline - & - & $3, \mathrm{pH} 7$ & -51 & +25 \\
\hline $\mathrm{Hx}, \mathrm{pH} 7$ & 1 & 4MAC, $\mathrm{pH} 7$ & -5 & +13 \\
\hline 4MAC, pH 5 & 1 & 4MAC, $\mathrm{pH} 7$ & -3 & +5 \\
\hline 4MAC, $\mathrm{pH} 7$ & 1 & 4MAC, $\mathrm{pH} 7$ & -14 & +11 \\
\hline 4MAC, pH 5 & 3 & 4MAC, $\mathrm{pH} 7$ & -9 & 0 \\
\hline 4MAC, $\mathrm{pH} 7$ & 3 & 4MAC, $\mathrm{pH} 7$ & -9 & -17 \\
\hline
\end{tabular}

${ }^{a}$ The pre-elution step was performed at $4{ }^{\circ} \mathrm{C}$. Hx, hexanoic acid $3 \mathrm{mM}$; IBU, rac-ibuprofen $3 \mathrm{mM}$; SAL, salicylic acid 3 mM; $4 \mathrm{MAC}$, tetramethylammonium chloride $500 \mathrm{mM} .{ }^{b}$ The elution step was performed at $37{ }^{\circ} \mathrm{C}, 3$ repeats; 4MAC, tetramethylammonium chloride $500 \mathrm{mM}$; NaCl $500 \mathrm{mM}$; TBT, rac-terbutaline $500 \mathrm{mM}$; 3, Boc-6Ahx-TTD-TBT $500 \mu \mathrm{M}$. ${ }^{c}$ The effect is reported in percentage normalized to the yield and apparent purity obtained in the reference condition. 
the result of a mild reactivity of these proteins towards the probe, emphasized by their large amount in plasma.

2.6.3. Elution step. hBChE was most efficiently eluted by a buffer containing tetramethylammonium chloride (4MAC), a weak hBChE activator/inhibitor which has also been used for eluting hBChE from Hupresin. ${ }^{42}$ A change of buffer $\mathrm{pH}$ did not show significant effects on the elution efficiency or selectivity of 4MAC (Table 4) and the same proteins were eluted at both $\mathrm{pH} 7$ and $\mathrm{pH}$ 5. The amount of eluted enzyme increased upon increasing the concentration of $4 \mathrm{MAC}$ up to $\sim 1 \mathrm{M}$ and the elution of the protein contaminants followed the same trend (Fig. 4b). Consistently to the proposed elution mechanism, the competition between $4 \mathrm{MAC}$ and the probe for the binding to hBChE reduced the carbamylation rate, while leaving the decarbamylation kinetics unaffected.

The incubation time was a major parameter affecting hBChE elution (Fig. 4c). In agreement with the proposed mechanism, the release of hBChE reached a plateau after $\sim 45$ min of incubation with $4 \mathrm{MAC}$, and followed the same profile that was calculated on the basis of the $k_{3}$ measured for compound 3 (Fig. 4c, inset). This evidence provided a further proof of the retention mechanism and indicated that the immobilization of the probe on the resin did not affect the decarbamylation kinetics.

Temperature was another major parameter affecting the elution as showed by the little loss in hBChE yield observed when additional pre-incubation steps with $4 \mathrm{MAC}$ were performed at $4{ }^{\circ} \mathrm{C}$ (at either $\mathrm{pH} 5$ and $\mathrm{pH}$ 7) before the usual elution with $4 \mathrm{MAC}$ at $37^{\circ} \mathrm{C}$ (Table 4 and Fig. 5). Consistently with the effect of temperature on catalytic rate constants, the decarbamylation rate of $\mathrm{hBChE}$ was reduced at low temperature, thus preventing the competitive effect of 4MAC. This was a further indication that hBChE retention involved a covalent interaction with the resin. The low temperature also prevented the release of the contaminants and the same amount of contaminants were obtained with or without the additional pre-incubation steps with $4 \mathrm{MAC}$ at $4{ }^{\circ} \mathrm{C}$ (Fig. 5). We interpreted this result as a further indication that also the other proteins might be retained through the formation of covalent bonds.

The yields of hBChE obtained with 4 MAC ranged from $17 \%$ to $36 \%$ of the loaded activity when fresh resin was used. The other eluting agents tested (i.e., compound 3, TBT, a weak hBChE inhibitor, ${ }^{43}$ and $\mathrm{NaCl}$, which was reported to reduce the carbamylation but not the decarbamylation rate $^{\mathbf{4 4}}$ ), were less efficient than 4MAC (Table 4).

2.6.4. Effect of repeated use of the resins on the yield. To assess the effect of the various experimental variables on the isolation performance we used an approximately $1 / 1$ plasma to resin volumetric ratio $(\mathrm{P} / \mathrm{R})$, which is considerably higher than ratios normally used in AC. A small excess of plasma was used in order to ensure that the resin would not dry during the incubation. This ratio allowed to keep the concentration of probe in the plasma-resin mixture as high as possible thus maximizing the carbamylation kinetic. Because of the $>1000$-fold molar excess of probe over hBChE in this condition, we anticipated that this $\mathrm{P} / \mathrm{R}$ ratio would not cause any overloading effect. The
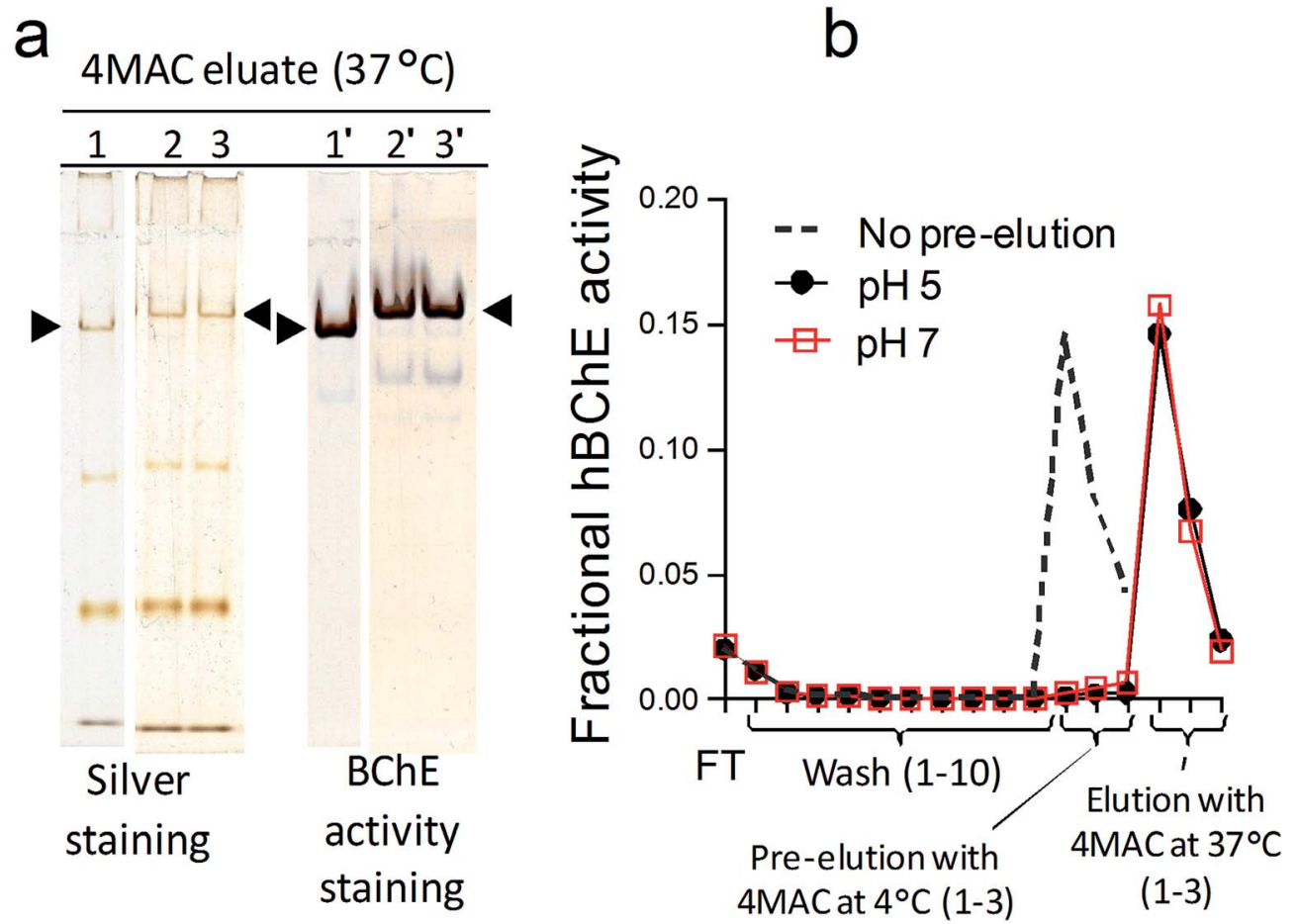

Fig. 5 (a) Non-denaturing PAGE showing the lack of effect of additional pre-elution steps performed using $4 \mathrm{MAC}$ at $4{ }^{\circ} \mathrm{C}$ on the amount of proteins eluted with $4 \mathrm{MAC}$ at $37^{\circ} \mathrm{C}$; lane 1 and $1^{\prime}$, elution with $4 \mathrm{MAC}, \mathrm{pH} 7$ at $37^{\circ} \mathrm{C}$ (no pre-elution); lane 2 and $2^{\prime}$, pre-elution with $4 \mathrm{MAC}$, pH 5 at $4{ }^{\circ} \mathrm{C}$ followed by elution with $4 \mathrm{MAC}, \mathrm{pH} 7$ at $37^{\circ} \mathrm{C}$; lane 3 and $3^{\prime}$, pre-elution with $4 \mathrm{MAC}, \mathrm{pH} 7$ at $4{ }^{\circ} \mathrm{C}$ followed by elution with $4 \mathrm{MAC}$, pH 7 at $37^{\circ} \mathrm{C}$. (b) hBChE activity of the eluates obtained in the three conditions; FT, flow-through fraction. 
evidence of absence of overloading effects was obtained by performing repeated incubations of the same resin aliquot with up to three plasma aliquots, which resulted in the same yield as the incubation with a single plasma aliquot (Fig. 6). However, only less than $50 \%$ of the loaded hBChE activity was eluted during the various steps of the isolation protocol and when the flow-through fraction was re-incubated with fresh resin, nearly no enzyme was retained (data not showed). Since the enzyme was able to completely recover its activity from the inhibition by compound 3 (Fig. 2d), it is unlikely that such large amount of enzyme remained attached to the resin after the elution step. A possible explanation for the low activity eluted was obtained from the analysis of the flow-through fraction which revealed a time-dependent increase of hBChE activity upon dilution. This suggested that a small, but significant amount of probe was released in solution and carbamylated part of the enzyme, thus preventing its interaction with the resin, reducing the final yield and causing an underestimation of the amount of hBChE released in each step. This issue was likely caused by the limited mechanical stability of sepharose and emphasized by the high reactivity of the probe towards hBChE. It is possible that other materials with better mechanical properties could have an advantage on this regard. Because of their non-porous nature, magnetic beads could be another potential choice with the advantage of having a much lower surface than porous materials. This would reduce the maximum probe density which, in turn, could reduce the amount of probe leaked in solution. With magnetic beads the use of spin filters would not be necessary and the isolation procedure could be performed in normal sample tubes. The use of a soluble form of the probe bearing an affinity or a clickable tag in place of the solid material could be a solution to completely avoid the leakage issue.

2.6.5. Optimization of the plasma to resin volumetric ratios $(\mathbf{P} / \mathbf{R})$ and final optimized protocol. The increase of the plasma to resin volume ratio $(\mathrm{P} / \mathrm{R})$ from $\sim 1 / 1$ to $\sim 3 / 1$ did not affect the yield of the isolated $\mathrm{hBChE}$ but a reduced yield was obtained with a further increase to $\sim 5 / 1$ (Fig. 7 and Table 5). In addition, the increase of $\mathrm{P} / \mathrm{R}$ reduced the relative abundance of contaminants (Fig. 7). An 850-fold purification factor was obtained for $\mathrm{hBChE}$ when a plasma aliquot was purified using all the conditions that minimized the retention of contaminant proteins (i.e. $\mathrm{P} / \mathrm{R}, \sim 3 / 1$; plasma incubation time, $10 \mathrm{~min}$; wash buffer temperature, $37^{\circ} \mathrm{C}$ ) (Table 6). The factor improved up to 1280 -fold by increasing the number of aliquots loaded at expense of the yield (Table 6). The results could be replicated, and the purification factor even improved up to $\sim 2500$-fold, using resin 6b (ESI, Scheme S1†) which was prepared by a simplified synthetic route involving the stepwise assembling of the probe on the sepharose matrix (Table 6). This emphasized the usefulness of employing a simple synthetic scheme to prepare the probe since more complicated synthetic routes do not usually perform well in a stepwise format when used to prepare mechanism-based resins. ${ }^{25}$

\section{Experimental}

\subsection{Materials}

A full list of chemicals, reagents, solvents and their providers is given as (ESI, S1†).
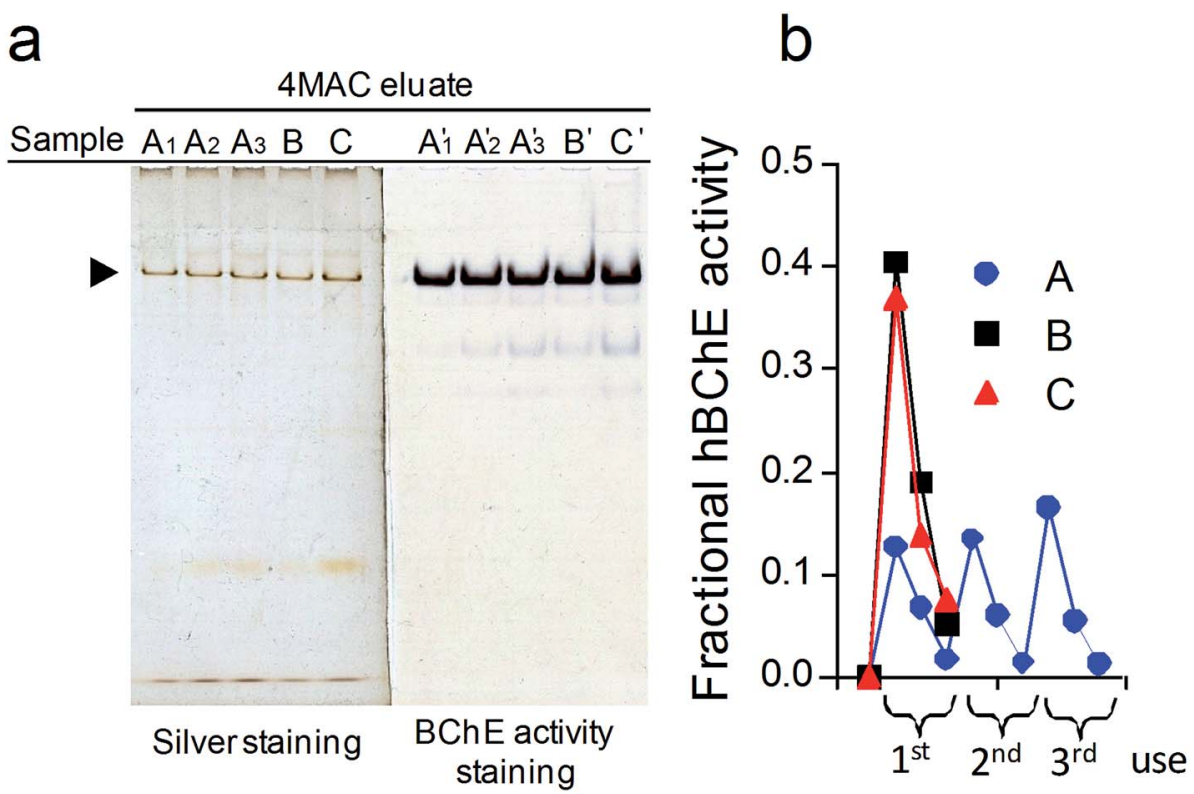

Fig. 6 Effect of repeated use of the resin on the yield and purity of hBChE isolated from plasma. The effect of repeated use on the isolation performance was evaluated by: (samples A1-A3) repeating three times the whole isolation protocol (i.e., each plasma incubation was followed by wash and elution steps); (sample B) repeating three times only the plasma incubation and the wash step followed by a single final elution ( $\times 3$ ); (sample C) repeating three times only the plasma incubation followed by a single wash step $(\times 10)$ and a single elution step $(\times 3)$. (a) Nondenaturing gel electrophoresis of the eluates obtained with the three protocols; samples $B$ and $C$ were diluted 3 -fold to match the amount of plasma loaded in samples A1-A3 (b) hBChE activity of the eluates obtained with the three protocols. 


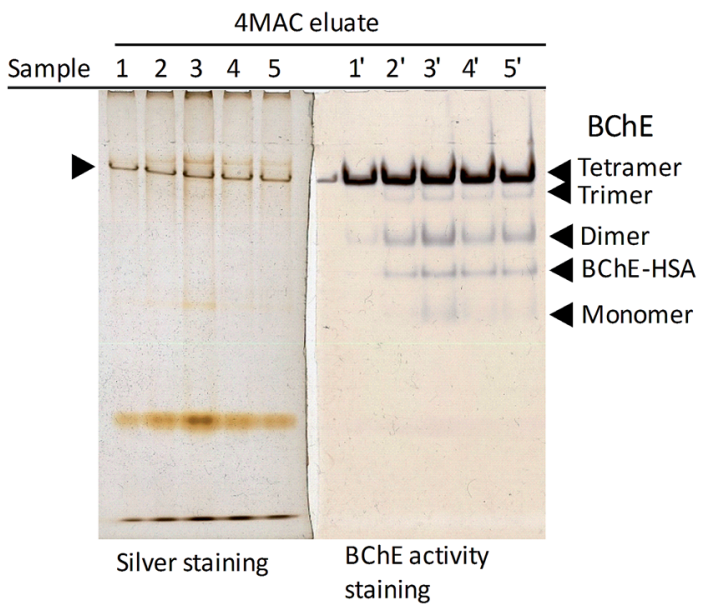

Fig. 7 Effect of plasma to resin volumetric ratio on the yield and purity of hBChE isolated from plasma. Non-denaturing gel electrophoresis of the eluates obtained the different conditions described in Table 5; the samples in lanes 4 and 5 were diluted 2.3-fold and 3.2-fold, respectively, to match the amount of plasma loaded in the other samples.

\subsection{Synthesis of compounds 1, 2, 3 and 4 (Strategy 1)}

The general methods used for the synthesis and characterization of the newly synthesized compounds is reported as (ESI, $\mathrm{S} 2 \dagger) .{ }^{1} \mathrm{H}-\mathrm{NMR},{ }^{13} \mathrm{C}-\mathrm{NMR}$ and HRMS spectra recorded for characterization are reported as (ESI $\dagger$ ), as indicated.

3.2.1 Compound 1. To a solution of Boc-6Ahx (2.5 g, 10.8 $\mathrm{mmol})$, in anhydrous ACN (50 mL), $3.0 \mathrm{~g}$ (18.5 mmol) of solid CDI were added under stirring, at room temperature. After $1 \mathrm{~h}$ the reaction vessel was placed in a $\mathrm{NaCl} /$ ice bath and $500 \mu \mathrm{L}$ of water were added to the mixture. After $20 \mathrm{~min}$ TTD $(25 \mathrm{~mL}$, $113.4 \mathrm{mmol}, 10.5$ eq.) was added dropwise to the reaction mixture. The reaction vessel was placed at room temperature and kept under stirring for $24 \mathrm{~h}$. After concentration in vacuo the residue was redissolved in $270 \mathrm{~mL}$ of water and the resulting solution was extracted with DCM $(300 \mathrm{~mL} \times 3)$. The extracts were pooled and washed with brine $(900 \mathrm{~mL})$, dried over anhydrous $\mathrm{Na}_{2} \mathrm{SO}_{4}$, filtered, and concentrated in vacuo. Purification of the residue by silica-gel column chromatography (115 g, mobile phase: DCM/MeOH 90/10, $\mathrm{NH}_{4} \mathrm{OH} 0.25 \% \mathrm{w} / \mathrm{v}$ ) gave Boc-6Ahx-TTD (1) (3.8 g, $8.8 \mathrm{mmol}, 82 \%$ yield) as a yellow viscous liquid.

Table 5 Effect of different plasma to resin volumetric ratios (P/R) on hBChE yield and purity

\begin{tabular}{lllll}
\hline Sample & $\begin{array}{l}\text { Plasma } \\
\text { volume }(\mu \mathrm{L})\end{array}$ & $\begin{array}{l}\text { Resin } \\
\text { amount }(\mathrm{mg})\end{array}$ & $\begin{array}{l}\text { Effect on } \\
\text { yield }^{a}(\%)\end{array}$ & $\begin{array}{l}\text { Effect on } \\
\text { purity }^{a}(\%)\end{array}$ \\
\hline 1 & 42 & 10 & -24 & +125 \\
2 & 42 & 25 & -8 & +17 \\
3 & 42 & 50 & Reference & Reference \\
4 & 95 & 50 & +1 & +25 \\
5 & 135 & 50 & +11 & +42
\end{tabular}

${ }^{a}$ The effect is reported in percentage normalized to the yield and apparent purity obtained in the reference condition.
Table 6 Effect of repeated use of resins $6 a$ and $6 b$ on hBChE isolates characteristics

\begin{tabular}{lllll}
\hline Resin & Sample $(\mu \mathrm{L})$ & $\begin{array}{l}\text { Yield } \\
(\%)\end{array}$ & $\begin{array}{l}\text { Specific activity } \\
\left(\mathrm{U} \mathrm{mg}^{-1}\right)\end{array}$ & $\begin{array}{l}\text { Purification } \\
\text { factor }\end{array}$ \\
\hline - & Original plasma & - & 0.03 & - \\
& $1 \times 70$ & 36.3 & 28.2 & 853 \\
6a & $4 \times 70$ & 24.4 & 38.2 & 1157 \\
& $8 \times 70$ & 7.3 & 42.3 & 1282 \\
6b & $1 \times 70$ & 29.1 & 28.7 & 837 \\
& $4 \times 70$ & 20.1 & 56.5 & 1649 \\
& $8 \times 70$ & 13.6 & 84.6 & 2470 \\
\hline
\end{tabular}

TLC: $R_{\mathrm{f}} 0.26 ;{ }^{1} \mathrm{HNMR}\left(400 \mathrm{MHz}, \mathrm{CDCl}_{3}\right.$, TMS) (Fig. S1†) $\delta 6.56$ $(1 \mathrm{H}, \mathrm{s}), 4.69(1 \mathrm{H}, \mathrm{s}), 3.68-3.53(12 \mathrm{H}, \mathrm{m}), 3.36(2 \mathrm{H}, \mathrm{q}, J=6.0 \mathrm{~Hz})$, $3.11(2 \mathrm{H}, \mathrm{q}, J=6.5 \mathrm{~Hz}), 2.82(2 \mathrm{H}, \mathrm{t}, J=7.6 \mathrm{~Hz}), 1.57-1.39(11 \mathrm{H}$, m), 1.39-1.29 (2H, m). ${ }^{1} \mathrm{HNMR}$ (400 MHz, $\mathrm{CDCl}_{3}, \mathrm{D}_{2} \mathrm{O}, \mathrm{TMS}$ ) (Fig. S2 $\dagger) \delta 4.78(2 \mathrm{H}, \mathrm{s}), 3.87-3.50(12 \mathrm{H}, \mathrm{m}), 3.35(2 \mathrm{H}, \mathrm{t}, J=6.2$ $\mathrm{Hz}), 3.10(2 \mathrm{H}, \mathrm{t}, J=7.1 \mathrm{~Hz}), 2.78(2 \mathrm{H}, \mathrm{t}, J=6.7 \mathrm{~Hz}), 2.15(2 \mathrm{H}, \mathrm{t}, J$ $=7.5 \mathrm{~Hz}), 1.84-1.68(4 \mathrm{H}, \mathrm{m}), 1.64(2 \mathrm{H}, \mathrm{p}, J=7.5 \mathrm{~Hz}), 1.56-1.38$ $(11 \mathrm{H}, \mathrm{m}), 1.38-1.26(2 \mathrm{H}, \mathrm{m}) .{ }^{13} \mathrm{CNMR}$ (101 $\left.\mathrm{MHz}, \mathrm{CDCl}_{3}\right)$ (Fig. S3†) $\delta 173.1,156.1,79.0,70.5,70.4,70.07,70.05,69.9,69.6$, 40.4, 39.6, 37.6, 36.5, 32.6, 29.7, 28.9, 28.4, 26.4, 25.4; HRMS (ESI-TOF) (Fig. S10 $\dagger$ ) $\mathrm{m} / \mathrm{z} \quad 434.3233 \quad$ (434.3225 calcd for $\mathrm{C}_{21} \mathrm{H}_{44} \mathrm{~N}_{3} \mathrm{O}_{6},[\mathrm{M}+\mathrm{H}]^{+}$).

3.2.2 Compound 2. To a solution of Boc-6Ahx-TTD (1) $(2.25 \mathrm{~g}, 5 \mathrm{mmol})$ in ice-cold water $(50 \mathrm{~mL}), 2.0 \mathrm{~g}(12.3 \mathrm{mmol})$ of solid CDI were added under stirring, at $4{ }^{\circ} \mathrm{C}$. After $30 \mathrm{~min}$ the reaction vessel was placed at room temperature for further $15 \mathrm{~min}$, then the reaction mixture was extracted with DCM $(50 \mathrm{~mL} \times 3)$. The extracts were pooled and concentrated in vacuo giving Boc-6Ahx-TTD-imidazole (2) (2.3 g, $4.3 \mathrm{mmol}, 87 \%$ yield) as a yellow viscous liquid.

TLC: $R_{\mathrm{f}}$ 0.42; HPLC (C18, UV shoulder $\left.230 \mathrm{~nm}\right) k^{\prime} 3.98\left(R_{\mathrm{t}} 7.0\right.$ min). ${ }^{1} \mathrm{HNMR}\left(400 \mathrm{MHz}, \mathrm{CDCl}_{3}\right.$ ) (Fig. S4 $\left.\dagger\right) \delta 8.21(1 \mathrm{H}, \mathrm{t}, J=1.1$ $\mathrm{Hz}), 7.56-7.46(2 \mathrm{H}, \mathrm{m}), 7.04(1 \mathrm{H}, \mathrm{t}, J=1.2 \mathrm{~Hz}), 6.41(1 \mathrm{H}, \mathrm{s}), 4.67$ $(1 \mathrm{H}, \mathrm{s}), 3.70-3.62(8 \mathrm{H}, \mathrm{m}), 3.59-3.52(4 \mathrm{H}, \mathrm{m}), 3.50(2 \mathrm{H}, \mathrm{t}, J=5.8$ $\mathrm{Hz}), 3.32(2 \mathrm{H}, \mathrm{q}, J=6.2 \mathrm{~Hz}), 3.10(2 \mathrm{H}, \mathrm{q}, J=6.7 \mathrm{~Hz}), 2.16(2 \mathrm{H}, \mathrm{t}, J$ $=7.5 \mathrm{~Hz}), 1.91(2 \mathrm{H}, \mathrm{dt}, J=12.0,5.6 \mathrm{~Hz}), 1.73(2 \mathrm{H}, \mathrm{p}, J=6.2 \mathrm{~Hz})$, $1.63(2 \mathrm{H}, \mathrm{p}, J=7.6 \mathrm{~Hz}), 1.53-1.39$ (11H, m), 1.38-1.27 (2H, m); ${ }^{13} \mathrm{CNMR}\left(101 \mathrm{MHz}, \mathrm{CDCl}_{3}\right.$ ) (Fig. S5†) $\delta$ 173.2, 156.1, 149.0, 135.9, 129.8, 116.5, 79.1, 70.4, 70.3, 70.2, 70.1, 69.9, 69.6, 40.4, 39.8, 37.5, 36.5, 29.8, 29.1, 28.6, 28.4, 26.4, 25.4; HRMS (ESI-TOF) (Fig. S11†) $m / z 528.3403$ (528.3392 calcd for $\mathrm{C}_{25} \mathrm{H}_{46} \mathrm{~N}_{5} \mathrm{O}_{7},[\mathrm{M}+$ $\mathrm{H}]^{+}$).

3.2.3 Compound 3. To a solution of Boc-6Ahx-Imidazole (2) (264 mg, $0.50 \mathrm{mmol})$ in ice-cold water $(5 \mathrm{~mL}), 275 \mathrm{mg}(1.0$ $\mathrm{mmol}$ ) of solid TBT were added under stirring, at $4{ }^{\circ} \mathrm{C}$. After $30 \mathrm{~min}$ the reaction mixture was placed at room temperature for further $4 \mathrm{~h}$, under stirring then the reaction mixture was diluted 4-fold with ammonium acetate (50 mM, pH 4.6) and extracted with DCM $(20 \mathrm{~mL} \times 3)$. The aqueous layer was divided in four $5 \mathrm{~mL}$ aliquots and subjected to $\mathrm{C} 18$ column chromatography $(2 \mathrm{~g}$ $\times 4)$, ammonium acetate $(50 \mathrm{mM}, \mathrm{pH} 4.6) / \mathrm{MeOH} 100 / 0(60 \mathrm{~mL})$, $80 / 20(20 \mathrm{~mL}), 50 / 50(8 \mathrm{~mL}), 0 / 100(8 \mathrm{~mL})$. The second $4 \mathrm{~mL}$ fraction eluted with ammonium acetate $(50 \mathrm{mM}, \mathrm{pH} 4.6) / \mathrm{MeOH}$ 
$50 / 50$ and the fractions eluted with $100 \% \mathrm{MeOH}$ were pooled and dried in vacuo to give the acetate salt of Boc-6Ahx-TTD-TBT (3) as a yellow-greenish viscous liquid. The amount of compound 3 in the final preparation, which contained traces of residual $\mathrm{MeOH}$ and ammonium acetate, was quantified by measuring the amount of terbutaline formed in alkaline conditions by HPLC (see paragraph 3.4.2) and the preparation was used without further purification (24\% yield).

TLC: $R_{\mathrm{f}}$ 0.23; HPLC (C18, UV max 274-277 nm, $\left.243 \mathrm{~nm}\right) k^{\prime}$ $2.48\left(R_{\mathrm{t}} 4.89 \mathrm{~min}\right) .{ }^{1} \mathrm{HNMR}\left(400 \mathrm{MHz}, \mathrm{CD}_{3} \mathrm{OD}\right)$ (Fig. S6†) $\delta 6.76$ $(1 \mathrm{H}, \mathrm{t}, J=1.8 \mathrm{~Hz}), 6.67(1 \mathrm{H}, \mathrm{t}, J=1.8 \mathrm{~Hz}), 6.49(1 \mathrm{H}, \mathrm{t}, J=2.2 \mathrm{~Hz})$, $4.83(1 \mathrm{H}, \mathrm{dd}, J=9.9,3.1 \mathrm{~Hz}), 3.68-3.55(10 \mathrm{H}, \mathrm{m}), 3.51(2 \mathrm{H}, \mathrm{t}, J=$ $6.2 \mathrm{~Hz}), 3.26(4 \mathrm{H}, \mathrm{dt}, J=13.5,6.8 \mathrm{~Hz}), 3.16(1 \mathrm{H}, \mathrm{dd}, J=12.4,3.2$ $\mathrm{Hz}), 3.06-2.97(3 \mathrm{H}, \mathrm{m}), 2.17(2 \mathrm{H}, \mathrm{t}, J=7.5 \mathrm{~Hz}), 1.86-1.69(4 \mathrm{H}$, $\mathrm{m}), 1.61(2 \mathrm{H}, \mathrm{p}, J=7.5 \mathrm{~Hz}), 1.53-1.40(11 \mathrm{H}, \mathrm{m}), 1.40-1.24(11 \mathrm{H}$, $\mathrm{m}) ;{ }^{13} \mathrm{CNMR}\left(101 \mathrm{MHz}, \mathrm{CD}_{3} \mathrm{OD}\right.$ ) (Fig. S7†) $\delta 178.6,176.1,159.8$, 157.1, 153.7, 144.9, 111.3, 111.0, 109.8, 79.8, 71.5, 70.21, 70.19, 70.3, 69.9, 69.8, 58.0, 49.9, 49.6, 41.2, 39.4, 37.8, 37.0, 30.7, 30.4, 28.8, 27.4, 26.7, 25.8, 23.1; HRMS (ESI-TOF) (Fig. S12 $) \mathrm{m} / \mathrm{z}$ 685.4385 (685.4382 calcd for $\left.\mathrm{C}_{34} \mathrm{H}_{61} \mathrm{~N}_{4} \mathrm{O}_{10},[\mathrm{M}+\mathrm{H}]^{+}\right)$.

3.2.4 Compound 4. To a solution of Boc-6Ahx-TTD-TBT (3) (36.1 mg, $0.05 \mathrm{mmol}$ ) in $500 \mu \mathrm{L}$ of $\mathrm{DCM} / \mathrm{MeOH} 90 / 10$ was added $100 \%$ TFA $(500 \mu \mathrm{L})$ dropwise, under stirring, at room temperature. After $20 \mathrm{~min}$ the reaction mixture was dried under vacuo to give the trifluoroacetate salt of 6Ahx-TTD-TBT (4) $(31.0 \mathrm{mg}$, $0.04 \mathrm{mmol}$, quantitative by TLC and HPLC analysis). The amount of compound $\mathbf{4}$ in the final preparation, which contained traces of residual $\mathrm{MeOH}$, was quantified by measuring the amount of terbutaline formed in alkaline conditions by HPLC (see paragraph 3.4.2) and the preparation was used without further purification.

TLC: $R_{\mathrm{f}}$ 0.03; HPLC (C18, UV max 276-277 nm, $\left.243 \mathrm{~nm}\right) k^{\prime} 0.04$ $\left(R_{\mathrm{t}} 1.47 \mathrm{~min}\right) .{ }^{1} \mathrm{HNMR}\left(400 \mathrm{MHz}, \mathrm{CD}_{3} \mathrm{OD}\right)$ (Fig. S8 $\dagger$ ) $\delta 6.76(1 \mathrm{H}, \mathrm{s})$, $6.67(1 \mathrm{H}, \mathrm{s}), 6.50(1 \mathrm{H}, \mathrm{t}, J=2.2 \mathrm{~Hz}), 4.85(2 \mathrm{H}, \mathrm{dd}, J=9.9,2.9 \mathrm{~Hz})$, $3.66-3.55(10 \mathrm{H}, \mathrm{m}), 3.51(2 \mathrm{H}, \mathrm{t}, J=6.1 \mathrm{~Hz}), 3.26(4 \mathrm{H}, \mathrm{dt}, J=11.4$, $6.8 \mathrm{~Hz}), 3.21-3.13(1 \mathrm{H}, \mathrm{m}), 3.06-2.96(1 \mathrm{H}, \mathrm{m}), 2.91(2 \mathrm{H}, \mathrm{t}, J=7.7$ $\mathrm{Hz}), 2.21(2 \mathrm{H}, \mathrm{t}, J=7.4 \mathrm{~Hz}), 1.85-1.71(4 \mathrm{H}, \mathrm{m}), 1.71-1.58(4 \mathrm{H}, \mathrm{m})$, 1.45-1.31 (11H, m); ${ }^{13} \mathrm{CNMR}\left(101 \mathrm{MHz}, \mathrm{CD}_{3} \mathrm{OD}\right)$ (Fig. S9†) $\delta 175.8,159.9,157.1,153.7,144.9,111.4,111.0,109.8,71.5,71.20$, 71.18, 70.3, 69.84, 69.75, 58.2, 49.9, 49.5, 40.5, 39.4, 37.8, 36.6, 30.7, 30.4, 28.2, 26.9, 26.3, 25.7; HRMS (ESI-TOF) (Fig. S13†) $\mathrm{m} / \mathrm{z}$ 585.3866 (585.3858 calcd for $\mathrm{C}_{29} \mathrm{H}_{53} \mathrm{~N}_{4} \mathrm{O}_{8},[\mathrm{M}+\mathrm{H}]^{+}$).

\subsection{Synthesis of the sepharose-supported probes}

3.3.1 Resin activation with $p$-nitrophenyl chloroformate (5) (Strategies 1 and 2), synthesis of sepharose-6Ahx-TTD-TBT (6a) (Strategy 1) and synthesis of sepharose-6Ahx (7) (Strategy 2). The activation of Sepharose CL-4B was performed in anhydrous conditions according to a previously published protocol, ${ }^{45}$ with minor modifications. The coupling protocols of this resin with compound 4 (Strategy 1, Scheme 1) and 6Ahx (Strategy 2, ESI, Scheme $\mathrm{S} 1 \dagger$ ) were adapted from a previously published protocol. ${ }^{46}$ A detailed description of these protocols is provided as (ESI, S3 $\dagger$ ).

3.3.2 Synthesis of sepharose-6Ahx-TTD (8) (Strategy 2). Icecold solutions of $\mathrm{HCl} 6 \mathrm{M}$ and $1 \mathrm{M}$ were added dropwise to an aliquot of ice-cold TTD $(3.5 \mathrm{~mL})$, to lower the $\mathrm{pH}$ to $\sim 5$. This solution was diluted with water to a final TTD concentration of $35 \%, \mathrm{v} / \mathrm{v}$. The $\mathrm{pH}$ of solution of $N$-(3-dimethylaminopropyl)- $N^{\prime}-$ ethylcarbodiimide hydrochloride (EDC, $100 \mathrm{mg} \mathrm{mL}^{-1}, 3 \mathrm{~mL}$ ) in water, prepared just before use, was adjusted to $\sim 5$ with $\mathrm{HCl}$ $1 \mathrm{M}$. The 6Ahx-derivatized sepharose CL-4B (7) ( $\sim 6 \mathrm{~g}$ ) was washed on a sintered glass funnel with $100 \mathrm{~mL}$ of ice-cold water, then was added to $8 \mathrm{~mL}$ of the TTD-HCl solution. After a brief shake, the solution of EDC was added dropwise to a final concentration of $20 \mathrm{mg} \mathrm{mL}{ }^{-1}$, then the reaction vessel was capped, placed on a rocking table and tumbled end-over-end overnight at room temperature. The resulting resin (8) was sequentially washed on a sintered glass funnel with the following ice-cold solutions (50 $\mathrm{mL}$ of each): sodium phosphate buffer (0.1 M, pH 7.5), containing $0.5 \mathrm{M} \mathrm{NaCl}$, distilled water, NaOAc buffer (0.1 M, pH 4), containing $0.5 \mathrm{M} \mathrm{NaCl}$, distilled water, $\mathrm{NaH}_{2} \mathrm{PO}_{4} 0.1 \mathrm{M} / \mathrm{EtOH} 80: 20$. The resin (8) was stored in $\mathrm{NaH}_{2} \mathrm{PO}_{4} 0.1 \mathrm{M} /$ EtOH $80: 20$ at $4{ }^{\circ} \mathrm{C}$.

3.3.3 Synthesis of sepharose-6Ahx-TTD-TBT (6b) (Strategy 2). The prepared sepharose-6Ahx-TTD (8), was washed on a sintered glass funnel with $100 \mathrm{~mL}$ of ice-cold water, then was suspended in $10 \mathrm{~mL}$ of ice-cold water, and the reaction vessel was placed on ice. Solid CDI (1.15 g) was added at once. The reaction mix were gently shaken for $10 \mathrm{~min}$, then was placed at room temperature. After $20 \mathrm{~min}$, solid TBT (2.5 g) was added under mild shaking. After $10 \mathrm{~min}$ the resin (6b) was sequentially washed on a sintered glass funnel with the following ice-cold solutions (100 mL each): distilled water, NaH2PO4 $0.1 \mathrm{M} /$ EtOH $80: 20$. The resin (6b) was stored in NaH2PO4 $0.1 \mathrm{M} /$ EtOH $80: 20$ at $4{ }^{\circ} \mathrm{C}$.

\subsection{Methods for the characterization of the solid-supported probes}

3.4.1 Determination of the amount of active carbonate groups on the resin. The amount of active $p$-nitrophenyl carbonate groups immobilized on the resin (5) and the residual carbonate groups after reaction with $6 \mathrm{Ahx}$ (7) were quantified by measuring the amount of $p$-nitrophenol released in alkaline conditions by spectrophotometry. ${ }^{46}$ The concentration of carbonate groups was calculated using $\varepsilon_{401} \mathrm{~nm}=18380 \mathrm{M}^{-1} \mathrm{~cm}^{-1} \cdot{ }^{47}$ A detailed description of the protocol is provided as (ESI, S4 $\dagger$ ). The amount of active groups immobilized on the resin used for Strategy 1 and Strategy 2 were $41 \mu \mathrm{mol} \mathrm{g}{ }^{-1}$ and $31 \mu \mathrm{mol} \mathrm{g}{ }^{-1}$ of wet (spin filtered) resin, respectively.

3.4.2 Determination of the amount of carbamate groups on the resins $(6 \mathbf{6}, \mathbf{6 b})$. The amount of carbamate coupled to the resins ( $6 \mathbf{a}$ and $\mathbf{6 b}$ ) was quantified by HPLC by measuring the amount of TBT released in alkaline conditions. About $180 \mathrm{mg}$ of the stored gel were washed on a $500 \mu \mathrm{L}$ spin filter with ice-cold distilled water $(500 \mu \mathrm{L} \times 10)$. Aliquots of the washed resin $(50 \mathrm{mg} \times 3)$ were incubated with $200 \mu \mathrm{L}$ of $\mathrm{NaOH} 1 \mathrm{M}$ on spin filters for $1 \mathrm{~h}$ at room temperature. The filtrate obtained after a brief spin (10 s) using a table centrifuge was collected. Then the resin was further washed with $\mathrm{NaOH} 1 \mathrm{M}(100 \mu \mathrm{L} \times 3)$ and the eluates obtained after a brief spin (10 s) using a table centrifuge were collected and pooled together with the first filtrate. An aliquot of $500 \mu \mathrm{L}$ of $\mathrm{HCl} 1 \mathrm{M}$ was added and the resulting solution was diluted 5-fold with ammonium acetate 
buffer $(50 \mathrm{mM}, \mathrm{pH} 4.6)$. This solution $(20 \mu \mathrm{L})$ was injected in the HPLC system described in the (ESI, S2 $\dagger$ ). The mobile phase consisted of ammonium acetate buffer (50 mM, pH 4.6)/MeOH $80: 20$. Standard TBT was analyzed in the same conditions (calibration curve $\left.(10-50 \mu \mathrm{M}): y=2639.7 x+2425.6, r^{2}=1\right)$. The same strategy was used to determine the content of compounds $\mathbf{3}$ and $\mathbf{4}$ in their respective preparations.

\subsection{Measurement of hBChE activity}

hBChE activity was measured in 96-well plates by an EnSpire Multimode 2300 plate reader (PerkinElmer, Waltham, MA) using a modified Ellman's spectrophotometric assay. ${ }^{48}$

A detailed description of the protocol is provided as (ESI, S5†).

\subsection{Characterization of the kinetics of the interaction between compound 3 (Boc-6Ahx-TTD-TBT) and hBChE}

3.6.1 Experimental protocol. The kinetics of the interaction between compound 3 and hBChE was determined by monitoring the time-dependent loss of hBChE activity upon incubation of diluted human plasma with different concentrations of compound 3 , at $\mathrm{pH} 8,37^{\circ} \mathrm{C}$. The substrate working solution and the assay buffer were prepared as described in the (ESI, S5 $\dagger$ ). The stock solution of compound 3 were prepared in ammonium acetate buffer $(50 \mathrm{mM}, \mathrm{pH} 4.6)$. The concentration of compound $\mathbf{3}$ in the stock solution was determined by measuring the amount of TBT formed after alkaline treatment similarly to the method described in paragraph 3.4.2. Solutions of plasma diluted $1: 300$ in assay buffer $(200 \mu \mathrm{L})$ were preincubated at $37{ }^{\circ} \mathrm{C}$ with solutions of compound $3(25 \mu \mathrm{L})$ at different concentrations (final concentrations, 29.5-1777 nM, in water). At set times (2-60 $\mathrm{min})$, the inhibition was stopped by adding the substrate working solution $(25 \mu \mathrm{L})$ and the residual hBChE activity $\left(\nu_{\mathrm{i}}\right)$ was spectrophotometrically determined as described in paragraph 3.5. A sample pre-incubated with water instead of compound 3 was measured in parallel to determine the maximum enzyme activity $\left(\nu_{0}\right)$.

3.6.2 Data analysis. The pseudo-first order and bimolecular carbamylation rate constants ( $k_{\text {obs }}$ and $k_{\mathrm{I}}$, respectively) were determined from the measured residual activity data as previously reported. ${ }^{7}$ The decarbamylation rate constant $\left(k_{3}\right)$ was determined from the same residual activity data by using a recently published method based on the analysis of the area under the inhibition-time curves (AUIC). ${ }^{29}$

3.6.3 hBChE activity recovery after inhibition by compound 3. The experiment was performed in order to prove the capacity of hBChE to completely recover its original activity after inhibition by compound 3 . The substrate working solution and the assay buffer were prepared as described in the (ESI, S5 $\dagger$ ). An aliquot of plasma $(8 \mu \mathrm{L})$ was pre-incubated with $2 \mu \mathrm{L}$ of a solution of compound 3 (3.75 $\mu \mathrm{M}$ in water) for $20 \mathrm{~min}$ at $37^{\circ} \mathrm{C}$ (final inhibitor concentration: $750 \mathrm{nM}$ ). An aliquot of $1.912 \mathrm{~mL}$ of assay buffer (pre-warmed at $37^{\circ} \mathrm{C}$ ) was then added to $8 \mu \mathrm{L}$ of the reaction mixture (dilution $1: 240$ ) and this solution was kept at $37{ }^{\circ} \mathrm{C}$. At set time points $225 \mu \mathrm{L}$ of this sample were added onto a well of a 96-well plate containing $25 \mu \mathrm{L}$ of substrate working solution. The hBChE activity $\left(\nu_{\mathrm{i}}\right)$ was spectrophotometrically determined at $37^{\circ} \mathrm{C}$ as described in the (ESI, S5 $\dagger$ ). A sample preincubated with water in place of compound 3 was analyzed in parallel to measure the maximum enzyme activity $\left(\nu_{0}\right)$.

\subsection{Investigation of the parameters affecting the isolation of hBChE from plasma}

3.7.1 General protocol. An aliquot of the resin under study was washed with ice-cold sodium phosphate $(100 \mathrm{mM}, \mathrm{pH} 7$ (PB), 100-fold the resin bed volume) on a spin filter (Biocomma, Shenzhen, PRC), then a weighted amount of wet (spin filtered) resin was placed on another spin filter and preincubated for $30 \mathrm{~min}$ with $\mathrm{PB}$, at $37{ }^{\circ} \mathrm{C}$. Unless otherwise specified, the resin amount was $50 \mathrm{mg}$. After a brief spin (10 s) using a table centrifuge, the selected volume of plasma (prewarmed at $37{ }^{\circ} \mathrm{C}$ for $30 \mathrm{~min}$ ) was added to the resin and incubated for the selected time at $37^{\circ} \mathrm{C}$. Unless otherwise specified, the plasma was $45 \mu \mathrm{L}$ and the incubation time was $30 \mathrm{~min}$. After a brief spin the flow-through fraction was collected to test the hBChE activity and the resin was washed with the selected buffer $(500 \mu \mathrm{L} \times 10-80)$ at $4{ }^{\circ} \mathrm{C}$ or $37{ }^{\circ} \mathrm{C}$. After each wash the buffer was collected to test the hBChE activity. Unless otherwise specified the wash buffer was $\mathrm{PB}(500 \mu \mathrm{L} \times 10)$ at $4{ }^{\circ} \mathrm{C}$. Finally the selected elution buffer was added to the resin $(100 \mu \mathrm{L} \times 3)$ and incubated for a selected time (10-60 min). Unless otherwise specified, the elution buffer contained 4MAC $500 \mathrm{mM}$ in PB and each incubation lasted $45 \mathrm{~min}$. Each eluted fraction was collected separately, concentrated and washed with PB $(4 \mathrm{~mL} \times$ 5) through an ultrafiltration unit (Amicon® Ultra-4 mL, $30 \mathrm{KDa}$ MWCO, $7500 \times g, 10 \mathrm{~min}, 4{ }^{\circ} \mathrm{C}$ ). An aliquot of the resulting solutions was analyzed to determine the hBChE activity and the yield. The rest was further concentrated with another ultrafiltration unit (Amicon ${ }^{\circledR}$ Ultra-500 $\mu \mathrm{L}, 30 \mathrm{KDa}$ MWCO, $14000 \times g$, $12 \mathrm{~min}, 4^{\circ} \mathrm{C}$ ). A $12 \mu \mathrm{L}$ aliquot of this concentrated preparation was analyzed by non-denaturing gel electrophoresis to evaluate the purity.

For sepharose-6Ahx-TTD-TBT (6a, Strategy 1), the effect on yield and purity of various protocol parameters was systematically investigated. In particular, the effect of resin amount (10 mg, $25 \mathrm{mg}, 50 \mathrm{mg})$, plasma volume $(42 \mu \mathrm{L}, 45 \mu \mathrm{L}, 95 \mu \mathrm{L}, 135$ $\mu \mathrm{L}$ ), incubation time in the load step (10 $\mathrm{min}, 20 \mathrm{~min}, 30 \mathrm{~min}$, $60 \mathrm{~min}$ ), nature of the wash buffer (PB, NaOAc (50 mM, pH 5), $\mathrm{NaCl}(200 \mathrm{mM}, 500 \mathrm{mM}, 1 \mathrm{M}, 1.5 \mathrm{M})$ in $\mathrm{PB})$, temperature of the wash buffer $\left(4^{\circ} \mathrm{C}\right.$ or $37{ }^{\circ} \mathrm{C}$, tested with both $\mathrm{PB}$ and NaOAc (50 mM, pH 5)), volume of the wash buffer $(500 \mu \mathrm{L} \times 10,500 \mu \mathrm{L}$ $\times 20,500 \mu \mathrm{L} \times 40$ ), tested with $\mathrm{NaCl} 1.5 \mathrm{M}$ in $\mathrm{PB}$ at $37^{\circ} \mathrm{C}$, nature of the elution buffer (rac-terbutaline hemisulfate (TBT) $500 \mathrm{mM}$ in $\mathrm{PB}, \mathrm{NaCl} 500 \mathrm{mM}$ in $\mathrm{PB}$, hexanoic acid $(\mathrm{Hx}) 3 \mathrm{mM}$ in $\mathrm{PB}$; ibuprofen (IBU) $3 \mathrm{mM}$ in $\mathrm{PB}$, salicylic acid (SAL) $3 \mathrm{mM}$ in $\mathrm{PB}$, compound $3500 \mu \mathrm{M}$ in $\mathrm{PB}, 4 \mathrm{MAC} 500 \mathrm{mM}$ in NaOAc $(50 \mathrm{mM}$, pH 5); 4MAC (0.5 mM, $1 \mathrm{mM}, 5 \mathrm{mM}, 20 \mathrm{mM}, 100 \mathrm{mM}, 500 \mathrm{mM}$, $1000 \mathrm{mM}$ ) in $\mathrm{PB})$, incubation time of the elution buffer (10$60 \mathrm{~min}$, tested with $4 \mathrm{MAC} 500 \mathrm{mM}$ in $\mathrm{PB}$ ), temperature of the elution buffer $\left(4^{\circ} \mathrm{C}\right.$ or $37{ }^{\circ} \mathrm{C}$, tested with 4 MAC $500 \mathrm{mM}$ at pH 5 and $\mathrm{pH} 7$ ).

3.7.2 Specific protocols. In the experiment aimed at demonstrating (1) the involvement of the active site of hBChE in 
the mechanism of retention, (2) the requirement of the presence of carbamate groups on the resin to achieve hBChE retention, and (3) that only active $\mathrm{hBChE}$ is retained (Fig. 3a), the plasma aliquots were pre-incubated with water or BMB $1 \mu \mathrm{M}$ ( $5 \mu \mathrm{L}$ of BMB $10 \mu \mathrm{M}$ in water added to $45 \mu \mathrm{L}$ of plasma, $30 \mathrm{~min}$, $\left.37{ }^{\circ} \mathrm{C}\right)$, or $\mathrm{HCl} 0.21 \mathrm{M}(2.5 \mu \mathrm{L}$ of $\mathrm{HCl} 4 \mathrm{M}$ added to $45 \mu \mathrm{L}$ of plasma, neutralized with $2.5 \mu \mathrm{L} \mathrm{NaOH} 4 \mathrm{M}$ after $15 \mathrm{~min}$ of incubation at $37^{\circ} \mathrm{C}$ ) then one aliquot of each sample was incubated with sepharose-6Ahx-TTD-TBT (6a) following the general protocol. In addition, an aliquot of the sample preincubated with water was loaded on a sample of resin 6 a whose carbamate groups were stripped through an alkaline treatment $(\mathrm{NaOH} 1 \mathrm{M}, 1 \mathrm{~h}$, room temperature, then washed with PB until neutrality).

In the experiment aimed at demonstrating that if denaturated, the hBChE bound to sepharose-6Ahx-TTD-TBT (6a) cannot be eluted (Fig. 3b), aliquots of plasma $(45 \mu \mathrm{L})$ were first loaded on aliquots of resin (50 mg) and incubated (30 min, 37 $\left.{ }^{\circ} \mathrm{C}\right)$, washed with $\mathrm{PB}\left(500 \mu \mathrm{L} \times 10\right.$ at $\left.4{ }^{\circ} \mathrm{C}\right)$ then the resin samples were spin-dried and treated with: $100 \mu \mathrm{L}$ of $\mathrm{PB}$ or NaOAc pH 5 and heated $\left(95^{\circ} \mathrm{C}, 5 \mathrm{~min}\right) ; 100 \mu \mathrm{L}$ of water/ACN $30 / 70 \mathrm{v} / \mathrm{v}\left(37^{\circ} \mathrm{C}\right.$, $30 \mathrm{~min}$ ); $95 \mu \mathrm{L}$ of $\mathrm{PB} / \mathrm{HCl} 4 \mathrm{M} 90 / 5 \mathrm{v} / \mathrm{v}$, neutralized with $5 \mu \mathrm{L}$ $\mathrm{NaOH} 4 \mathrm{M}$ after $15 \mathrm{~min}$ of incubation at $37{ }^{\circ} \mathrm{C}$. An untreated sample was prepared in parallel for reference.

In the experiments aimed at demonstrating the effect of temperature in the elution step (Table 4 and Fig. 5), samples of resin incubated with plasma and washed according to the general protocol, were pre-incubated $45 \mathrm{~min}(\times 1$ or $\times 3)$ with $100 \mu \mathrm{L}$ of $4 \mathrm{MAC}$ at $4{ }^{\circ} \mathrm{C}$, pH 5 or $\mathrm{pH} 7$. The eluate obtained from this pre-incubation was collected for analysis. The resin samples were then incubated and eluted with $4 \mathrm{MAC} 500 \mathrm{mM}$, $\mathrm{pH} 7$ at $37^{\circ} \mathrm{C}$, as in the general protocol.

In order to understand if the yield was limited by overloading effects, we evaluated the effect of three repeated incubations of $70 \mu \mathrm{L}$ of plasma on the isolation performance, using three slightly different protocols (Fig. 6): (sample A) repeating the plasma incubation-wash-elution steps three times; (sample B) repeating three times only the plasma incubation and the wash steps followed by a single elution step; (sample C) repeating three times only the plasma incubation followed by a single wash step and a single elution step. Resin amount, $25 \mathrm{mg}$; plasma incubation step, $10 \mathrm{~min}$; wash step, $500 \mu \mathrm{L} \mathrm{PB} \times 10$, at $37^{\circ} \mathrm{C}$; elution step, $100 \mu \mathrm{L} 4 \mathrm{MAC} 500 \mathrm{mM} \times 3$, at $37^{\circ} \mathrm{C}$.

In order to evaluate the possibility of using the resin more than three times, three samples (25 mg) of the sepharose-6AhxTTD-TBT under study (6a, Strategy 1, or $\mathbf{6 b}$, Strategy 2) were incubated with one, four or eight aliquots of human plasma (each aliquot, $70 \mu \mathrm{L}$ ), respectively. Each incubation lasted for $10 \mathrm{~min}$, and was performed at $37^{\circ} \mathrm{C}$. After the last incubations, the resin samples were washed with $\mathrm{PB}(500 \mu \mathrm{L} \times 10,500 \mu \mathrm{L} \times$ 40 and $500 \mu \mathrm{L} \times 80$, respectively, at $37^{\circ} \mathrm{C}$ ) and incubated with 4 MAC $(100 \mu \mathrm{L} \times 3)$ for $45 \mathrm{~min}$ at $37{ }^{\circ} \mathrm{C}$. The eluates were concentrated and washed with $\mathrm{PB}(400 \mu \mathrm{L} \times 10)$ through ultrafiltration units (Amicon ${ }^{\circledR}$ Ultra- $0.5 \mathrm{~mL}, 30 \mathrm{KDa}$ MWCO, $14000 \times g$, $15 \mathrm{~min}, 4{ }^{\circ} \mathrm{C}$ ), then they were characterized for their total protein content (paragraph 3.8) and hBChE activity (paragraph 3.5) to calculate the specific activities of hBChE and the purification factors (Table 6).

3.7.3 Comparison of the theoretical and experimental kinetics of $\mathbf{h B C h E}$ release. The theoretical elution profile of hBChE from resin 6 a was based on the decarbamylation rate constant $\left(k_{3}\right)$ measured for hBChE inhibited by compound 3 (Table 1) and was calculated by the WEB server ENZO (http:// enzo.cmm.ki.si). ${ }^{49}$ The theoretical profile was compared to the hBChE activity eluted using $3 \times 4 \mathrm{MAC}$ incubations for different incubation times (Fig. 4c, inset). The activity eluted with $3 \times$ 60 min incubation with $4 \mathrm{MAC}$ was set as $95 \%$ of the maximum elutable hBChE activity based on an approximate estimation and the other experimental values were normalized accordingly.

\subsection{Methods for the characterization of the isolated hBChE}

3.8.1 Non-denaturing polyacrylamide gel electrophoresis. Non-denaturing gel electrophoresis was carried out on housemade $8 \%$ polyacrylamide gel slabs with a $5 \%$ stacking gel. A $12 \mu \mathrm{L}$ aliquot of resin eluate was mixed with $12 \mu \mathrm{L}$ of a solution composed of bromophenol blue (2 mg), glycerol (4 mL), $62.5 \mathrm{mM}$ Tris- $\mathrm{HCl}$ (pH 6.8) (1 mL). Aliquots of this solution (10 $\mu \mathrm{L} \times 2$ ) were loaded in duplicate on the left and right sides of the gel.

The electrophoresis was at run at constant voltage $(80 \mathrm{~V})$ using a $0.05 \mathrm{M}$ Tris-0.38 $\mathrm{M}$ glycine buffer ( $\mathrm{pH} 8.3$ ) at $4{ }^{\circ} \mathrm{C}$ and was stopped just before the bromophenol blue could elute from the gel $(\sim 1.5 \mathrm{~h})$. The gel was then cut in half: one half was stained for BChE activity by the method of Karnovsky and Roots $^{\mathbf{5 0}}$ using $S$-butyrylcholine iodide as the substrate; the other half was developed by silver staining (short silver nitrate protocol). ${ }^{51}$ The optical density of the bands developed by silver staining was used to evaluate differences in purity (apparent purity) among the samples separated in the same gel.

3.8.2. Total protein quantification, calculation of yield and purification factor. The total protein content in the eluates was measured in 96-well plates by an EnSpire Multimode 2300 plate reader (PerkinElmer, Waltham, MA) by Bradford assay using bovine serum albumin (BSA) as the calibration standard.

The yield was calculated as the ratio between the hBChE activity in the eluate and the hBChE activity measured for the loaded plasma. The specific activity was calculated as the ratio between the hBChE activity and the total protein content of the sample. The purification factor was obtained as the ratio between the specific activity of hBChE in the eluate and that in plasma.

\subsubsection{Proteomic analysis}

3.8.3.1 Sample preparation. Aliquots of the ultrafiltrates obtained with resin 6a showed in Fig. 7, lanes 4 and 5 were prepared for proteomic analysis by using a previously published filter-assisted sample preparation (FASP) protocol, with minor modifications. ${ }^{52}$ A detailed description of the protocol is provided as (ESI, S6†). The resulting solution was analyzed by $\mathrm{UPLC}^{-H D M S}{ }^{\mathrm{E}}$.

3.8.3.2 UPLC. The tryptic digest peptides were separated on a UPLC system (I class, waters) equipped with a Acquity UPLC BEH C18, $1.7 \mu \mathrm{m}(100 \mathrm{~mm} \times 2.1 \mathrm{~mm}$ i.d. $), 130$ Å. Mobile phase 
A was $0.1 \%$ formic acid in water, mobile phase $\mathrm{B}$ was $0.1 \%$ formic acid in ACN. The peptides were eluted with a $3.04 \mathrm{~B} \% / \mathrm{CV}$ (CV, column volume) linear gradient as follows (time, flow rate,

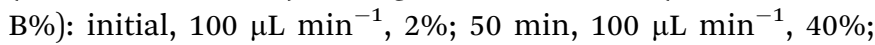
$51 \mathrm{~min}, 600 \mu \mathrm{L} \min ^{-1}, 80 \%$; $55 \mathrm{~min}, 600 \mu \mathrm{L} \min ^{-1}, 80 \%$; $56 \mathrm{~min}, 600 \mu \mathrm{L} \min ^{-1}, 2 \%$; $58.5 \mathrm{~min}, 600 \mu \mathrm{L} \min ^{-1}, 2 \%$; $58.6 \mathrm{~min}, 100 \mu \mathrm{L} \min ^{-1}, 2 \%$; $60 \mathrm{~min}, 100 \mu \mathrm{L} \min ^{-1}, 2 \%$. Column temperature, $55{ }^{\circ} \mathrm{C}$; sample temperature, $10{ }^{\circ} \mathrm{C}$. The lockmass compound leucine enkephalin $200 \mathrm{pg} \mu \mathrm{L}^{-1}(\mathrm{~m} / \mathrm{z}$ $556.2771)$ in water/ACN (50/50, 0.1\% formic acid) was delivered to the lockspray source of the mass spectrometer at $5 \mu \mathrm{L} \mathrm{min}{ }^{-1}$ using the fluidics of the MS apparatus.

3.8.3.3 Mass spectrometry. The mass spectrometry of the tryptic peptides separated by chromatography was performed on-line by a Q-TOF mass spectrometer (Synapt G2-S HDMS, Waters) equipped with an ESI source. The mass spectrometer was operated in positive and resolution modes. Data were acquired with the instrument operating in $\mathrm{MS}^{\mathrm{E}}$ mode with ion mobility enabled (HDMS $\left.{ }^{\mathrm{E}}\right) .{ }^{52}$ Source settings: source (capillary $3.00 \mathrm{kV}$, cone $35 \mathrm{kV}$ offset $80 \mathrm{kV}$ ), temperature (source $100{ }^{\circ} \mathrm{C}$, desolvation $350{ }^{\circ} \mathrm{C}$ ), gas flows (cone gas $50 \mathrm{~L} \mathrm{~h}^{-1}$, desolvation gas $500 \mathrm{~L} \mathrm{~h}^{-1}$, nebulizer 6.0 bar), lockspray capillary $2.50 \mathrm{kV}$. Quad profile (mass, dwell time, ramp time): 1 (400, 20, 20), 2 $(500,20,40), 3$ (1000). Data were acquired collecting spectra in the $50-2000 \mathrm{~m} / \mathrm{z}$ range every $0.6 \mathrm{~s}$ (data format: continuum) using the following ion mobility-dependent energy profile: bin 1-20, constant $17 \mathrm{eV}$; bin 20-110 ramp from $17 \mathrm{eV}$ to $45 \mathrm{eV}$; bin 110 to 200 ramp from $45 \mathrm{eV}$ to $60 \mathrm{eV} .^{52}$ The lockspray signal was measured by averaging $3 \times 0.6 \mathrm{~s}$ scans every $30 \mathrm{~s}$, within a mass window of \pm 0.5 Da.

3.8.3.4 Data processing, protein identification and semiquantification. The LC-HDMS ${ }^{\mathrm{E}}$ data were processed using ProteinLynx Global SERVER (PLGS) v2.5.2 (Waters), using the following parameters: UniprotKB Homo sapiens proteome dataset (UP000005640, reviewed, 20416 entries, 30-04-2019); peptide and fragment tolerance, automatic (the software set $5 \mathrm{ppm}$ and $13 \mathrm{ppm}$, respectively); maximum trypsin missed cleavages, 1; maximum protein mass $500 \mathrm{kDa}$; fixed modification, carbamidomethylation at Cys; variable modifications, oxidation at Met; false positive rate, $4 \%$. Minimum fragment ion matches per peptide, 1 ; minimum fragment ion matches per protein, 3 ; minimum peptide matches per protein, 1. Processing parameters: low energy threshold, 10 counts; elevated energy threshold, 5 counts; intensity threshold, 500 counts. A protein score above 5 was set post-processing (100 is a typical accepted threshold for reliable identification). Protein semiquantification (relative abundance) was based on the integrated peptide ion intensities according to the Top3 method. ${ }^{53}$

\section{Conclusions}

In summary, the results demonstrated that the designed probe captured and released hBChE from plasma with high selectivity and reasonable yields. The best purification factor obtained was similar to that obtained with Hupresin, the best AC method for the purification of hBChE from plasma currently available ( $\sim 2000$-fold). ${ }^{38}$ The yield was probably limited by the release of small quantities of probe from the resin. The main parameters affecting the performance were the incubation time used in the load and the elution steps, the $\mathrm{P} / \mathrm{R}$, the elution temperature and the nature and concentration of the eluting agent whereas all the other parameters investigated had limited effect. The carbamate resin could be prepared using simple and inexpensive synthetic steps either by coupling a fully synthesized probe with an activated resin or by building the probe on the resin by a step-by-step procedure, without major differences in performance between the two routes. The prepared resins allowed to process up to about $8.5 \mathrm{~mL}$ of plasma per $\mathrm{g}$ of resin with constant performance.

In conclusion, this work demonstrated the feasibility of using mechanism-based probes bearing carbamate moieties for the selective and kinetically-controlled capture and release of active hBChE from complex proteomes. The method is based on the manipulation of the kinetic equilibrium between the two reactions catalyzed by the target enzyme and does not require the use of reactivating reagents. Overall the method is simple and fast and its use is similar to that of traditional AC resins. In contrast to traditional AC methods, this approach enabled to retain all the active $\mathrm{hBChE}$ isoenzymes. Since the method is based on the general catalytic cycle of $\mathrm{mSHs}$, we expect this approach to be applicable to other enzymes of the family, by selecting a suitable target-selective feature to link to the carbamate group. Further research is required to establish the relationship between probe-enzyme reaction kinetics and purification performance, to fully understand the reasons underlying the limited yield and reusability and to explore other possible setups.

\section{Conflicts of interest}

There are no conflicts to declare.

\section{Acknowledgements}

This work was supported by the Fundamental Research Fund for the Central Universities, China [Grant 2014ZM0053] and the Research Start-up Funds of South China University of Technology [Grants x2sw/D6191290 and j2rs/D6173430].

\section{Notes and references}

1 G. M. Simon and B. F. Cravatt, J. Biol. Chem., 2010, 285, 11051-11055.

2 J. Z. Long and B. F. Cravatt, Chem. Rev., 2011, 111, 60226063.

3 T. Fukami and T. Yokoi, Drug Metab. Pharmacokinet., 2012, 27, 466-477.

4 B. Chen, S.-S. Ge, Y.-C. Zhao, C. Chen and S. Yang, RSC Adv., 2016, 6, 113327-113343.

5 S. R. Feaster and D. M. Quinn, Methods Enzymol., 1997, 286, 231-252.

6 D. A. Bachovchin, T. Ji, W. Li, G. M. Simon, J. L. Blankman, A. Adibekian, H. Hoover, S. Niessen and B. F. Cravatt, Proc. Natl. Acad. Sci. U. S. A., 2010, 107, 20941-20946. 
7 M. Pistolozzi, H. Du, H. Wei and W. Tan, Drug Metab. Dispos., 2015, 43, 344-352.

8 H. Zhou, Q. Xiao, W. Tan, Y. Zhan and M. Pistolozzi, J. Pharm. Biomed. Anal., 2017, 144, 167-174.

9 M. P. Patricelli, H. A. Lashuel, D. K. Giang, J. W. Kelly and B. F. Cravatt, Biochemistry, 1998, 37, 15177-15187.

10 Y. Ben Ali, H. Chahinian, S. Petry, G. Muller, F. Carrière, R. Verger and A. Abousalham, Biochemistry, 2004, 43, 92989306.

11 Z. Rashid, H. Naeimi, A.-H. Zarnani, M. Nazari, M.-R. Nejadmoghaddam and R. Ghahremanzadeh, RSC Adv., 2016, 6, 36840-36848.

12 K. Salimi, D. D. Usta, İ. Koçer, E. Çelik and A. Tuncel, RSC Adv., 2017, 7, 8718-8726.

13 X. Yang, M. Pistolozzi and Z. Lin, Biotechnol. Lett., 2018, 40, 745-753.

14 T. Tsujita, H. Ninomiya and H. Okuda, J. Lipid Res., 1989, 30, 997-1004.

15 P. Masson and O. Lockridge, Arch. Biochem. Biophys., 2010, 494, 107-120.

16 J. F. Breyer, C. Schmidt, B. Mizaikoff, F. Worek and H. Thiermann, Drug Test. Anal., 2015, 7, 947-956.

17 Y. Liu, M. P. Patricelli and B. F. Cravatt, Proc. Natl. Acad. Sci. U. S. A., 1999, 96, 14694-14699.

18 D. Kidd, Y. Liu and B. F. Cravatt, Biochemistry, 2001, 40, 4005-4015.

19 B. F. Cravatt, A. T. Wright and J. W. Kozarich, Annu. Rev. Biochem., 2008, 77, 383-414.

20 J. L. Counihan, B. Ford and D. K. Nomura, Curr. Opin. Chem. Biol., 2016, 30, 68-76.

21 D. K. Nomura, J. Z. Long, S. Niessen, H. S. Hoover, S. W. Ng and B. F. Cravatt, Cell, 2010, 140, 49-61.

22 D. A. Bachovchin, T. Ji, W. Li, G. M. Simon, J. L. Blankman, A. Adibekian, H. Hoover, S. Niessen and B. F. Cravatt, Proc. Natl. Acad. Sci. U. S. A., 2010, 107, 20941-20946.

23 D. K. Nomura and J. E. Casida, J. Agric. Food Chem., 2011, 59, 2808-2815.

24 D. Medina-Cleghorn, A. Heslin, P. J. Morris, M. M. Mulvihill and D. K. Nomura, ACS Chem. Biol., 2014, 9, 423-432.

25 V. Delorme, B. Raux, R. Puppo, J. Leclaire, J. F. Cavalier, S. Marc, P. K. Kamarajugadda, G. Buono, F. Fotiadu, S. Canaan and F. Carrière, Biochimie, 2014, 107(Pt A), 124.

26 Y. Ashani and I. B. Wilson, Biochim. Biophys. Acta, 1972, 276, 317-322.

27 H. F. Voss, Y. Ashani and I. B. Wilson, Methods Enzymol., 1974, 34, 581-591.

28 A. Tunek and L. A. Svensson, Drug Metab. Dispos., 1988, 16, 759-764.

29 Q. Xiao, H. Zhou, H. Wei, H. Du, W. Tan, Y. Zhan and M. Pistolozzi, J. Pharm. Biomed. Anal., 2017, 144, 175-182.
30 G. Voss, Arch. Toxicol., 1976, 36, 117-120.

31 M. Rotenberg and S. Almog, Clin. Chim. Acta, 1995, 240, 107116.

32 E. Groner, Y. Ashani, D. Schorer-Apelbaum, J. Sterling, Y. Herzig and M. Weinstock, Mol. Pharmacol., 2007, 71, 1610-1617.

33 K. J. Padiya, S. Gavade, B. Kardile, M. Tiwari, S. Bajare, M. Mane, V. Gaware, S. Varghese, D. Harel and S. Kurhade, Org. Lett., 2012, 14, 2814-2817.

34 J. Stojan, M. Golicnik, M. T. Froment, F. Estour and P. Masson, Eur. J. Biochem., 2002, 269, 1154-1161.

35 T. L. Rižne, Biochem. Mol. Biol. Educ., 2014, 42, 152-159.

36 B. Li, M. Sedlacek, I. Manoharan, R. Boopathy, E. G. Duysen, P. Masson and O. Lockridge, Biochem. Pharmacol., 2005, 70, 1673-1684.

37 O. Lockridge, L. M. Schopfer, G. Winger and J. H. Woods, J. Med. Chem. Biol. Radiol. Def., 2005, 3, nihms5095.

38 S. Onder, E. David, O. Tacal, L. M. Schopfer and O. Lockridge, Front. Pharmacol., 2017, 8, 713.

39 N. L. Anderson and N. G. Anderson, Mol. Cell. Proteomics, 2002, 1, 845-867.

40 E. Chosson, S. Uzan, F. Gimenez, I. W. Wainer and R. Farinotti, Chirality, 1993, 5, 71-77.

41 C. Bertucci, M. Pistolozzi, G. Felix and U. H. Danielson, J. Sep. Sci., 2009, 32, 1625-1631.

42 O. Lockridge, E. David, L. M. Schopfer, P. Masson, X. Brazzolotto and F. Nachon, J. Chromatogr. B: Anal. Technol. Biomed. Life Sci., 2018, 1102-1103, 109-115.

43 Z. Kovarik and V. Simeon-Rudolf, J. Enzyme Inhib. Med. Chem., 2004, 19, 113-117.

44 V. Tõugu and T. Kesvatera, Biochim. Biophys. Acta, 1996, 1298, 12-30.

45 W. H. Scouten, Curr. Protoc. Protein Sci., 2001, ch. 9, unit 9.3. 46 T. Miron and M. Wilcheck, Methods Enzymol., 1987, 135, 8490.

47 G. N. Bowers Jr, R. B. McComb, R. C. Christensen and R. Schaffer, Clin. Chem., 1980, 26, 724-729.

48 G. L. Ellman, K. D. Courtney, V. Jr Ander and R. M. Featherstone, Biochem. Pharmacol., 1961, 7, 88-95.

49 S. Bevc, J. Konc, J. Stojan, M. Hodošček, M. Penca, M. Praprotnik and D. Janežič, PLoS One, 2011, 6, e22265.

50 M. J. Karnovsky and L. Roots, J. Histochem. Cytochem., 1964, 12, 219-221.

51 M. Chevallet, S. Luche and T. Rabilloud, Nat. Protoc., 2006, 1, 1852-1858.

52 U. Distler, J. Kuharev, P. Navarro and S. Tenzer, Nat. Protoc., 2016, 11, 795-812.

53 J. C. Silva, M. V. Gorenstein, G.-Z. Li, J. P. C. Vissers and S. J. Geromanos, Mol. Cell. Proteomics, 2006, 5, 144-156. 